\title{
Métodos de extração, formas e toxicidade de alumínio na soja cultivada em solos com elevados teores de $\mathrm{Al}-\mathrm{KCl}$
}

\author{
Methods of extraction, forms and aluminum toxicity in soybean cultivated in soils \\ with high Al-KCl
}

\section{Gabriel Octávio de Mello CUNHA ${ }^{1}$; Jaime Antonio de ALMEIDA²; Francisco Alexandre de MORAIS; Matheus Rodrigo MACHADO ${ }^{3}$}

\begin{abstract}
${ }^{1}$ Autor para correspondência: Doutor em Ciência do Solo, Universidade do Estado de Santa Catarina, Centro de Ciências Agroveterinárias, Departamento de Solos e Recursos Naturais, Lages, Santa Catarina, Brasil. E-mail: gabriel.cunha4@gmail.com

${ }^{2}$ Doutor em Ciência do Solo, Professor Titular, Universidade do Estado de Santa Catarina, Centro de Ciências Agroveterinárias, Departamento de Solos e Recursos Naturais, Lages, Santa Catarina, Brasil. E-mail: jaime.almeida@udesc.br

${ }^{3}$ Doutor em Ciência do Solo, Pesquisador, Instituto Rio Grandense do Arroz. E-mail: francisco-morais@irga.rs.gov.br

${ }^{4}$ Mestrando em Ciência do Solo, Universidade do Estado de Santa Catarina, Centro de Ciências Agroveterinárias, Departamento de Solos e Recursos Naturais, Lages, Santa Catarina, Brasil. E-mail: matheusrmachado.android@gmail.com
\end{abstract}

Recebido em: 10-10-2018; Aceito em: 19-01-2019

\begin{abstract}
Resumo
O alumínio (Al) "trocável" do solo é tradicionalmente extraído com solução de $\mathrm{KCl} 1 \mathrm{~mol} \mathrm{~L}^{-1}(\mathrm{Al}-\mathrm{KCl})$. O emprego desta solução pode superestimar o Al trocável, implicando uma interpretação equivocada dos efeitos tóxicos desse elemento às plantas. O estudo objetivou avaliar, por meio de extrações químicas sequenciais (ES) e não sequenciais (ENS), as possíveis frações de Al que possam estar contribuindo para a superestimação do Al trocável e se as mesmas estão relacionadas com sua toxicidade nas plantas de soja cultivadas em casa de vegetação. Também, identificar a eficácia do $\mathrm{KCl} 1 \mathrm{~mol} \mathrm{~L}^{-1} \mathrm{em}$ extrair somente as frações tóxicas do $\mathrm{Al}$ e o extrator que melhor estimou o potencial tóxico do mesmo às plantas.Para isso, foram realizadas ES utilizando os extratores, na ordem, $\mathrm{CaCl}_{2}$ 0,01 mol L-1, $\mathrm{KCl} 0,1$ e $1 \mathrm{~mol} \mathrm{~L}^{-1}$ e oxalato de amônio $0,2 \mathrm{~mol} \mathrm{~L}^{-1}$ e ENS com uma única extração, utilizando-se somente das três últimas soluções. O Al proveniente de polímeros amorfos foram responsáveis pela superestimação do Al-KCl. O Al extraído pelos diferentes extratores não está relacionado com sua toxicidade às plantas. Para os solos AC9 e RS não houve resposta das plantas de soja à calagem e tampouco manifestação expressiva de toxicidade de Al nas mesmas. Nos solos PE, BR e CB, o KCl $1 \mathrm{~mol} \mathrm{~L}^{-1}$ foi eficaz na estimativa do Al trocável e do seu potencial tóxico. $O \mathrm{CaCl}_{2} \quad 0,01 \mathrm{~mol} \mathrm{~L}^{-1}$ foi o extrator que melhor identificou o potencial tóxico do Al nos solos avaliados.
\end{abstract}

Palavras-chave adicionais: alumínio trocável; extratores; métodos de extração; polímeros de Al amorfos.

\begin{abstract}
The soil "exchangeable" aluminum (Al) is traditionally extracted with $\mathrm{KCl} 1 \mathrm{~mol} \mathrm{~L}^{-1}$ solution (Al-KCl). The use of this solution may overestimate Al exchangeable, implying a misinterpretation of the toxic effects of this element on plants. The objective of this study was to evaluate the possible fractions of Al which may be contributing to the overestimation of $\mathrm{Al}$ exchangeable and whether they are related to its phytotoxicity by means of sequential (ES) and non-sequential (ENS) chemical extractions. Also, to identify the efficacy of $\mathrm{KCl} 1 \mathrm{~mol} \mathrm{~L}^{-1}$ in extracting only the toxic forms of $\mathrm{Al}$ and the extractor that best estimates the toxic potential of this element to soybean plants cultivated in greenhouse. For this purpose, ES was performed usingthe extractors, in order, $\mathrm{CaCl}_{2} 0.01 \mathrm{~mol} \mathrm{~L}^{-1}$, $\mathrm{KCl} 0.1$ and $1 \mathrm{~mol} \mathrm{~L}^{-1}$ and $0.2 \mathrm{~mol} \mathrm{~L}^{-1}$ ammonium oxalate and ENS with a single extraction, using only the last three solutions. Al from amorphous polymers were responsible for the overestimation of $\mathrm{Al}-\mathrm{KCl}$. Al extracted by different extractors is not related to Al toxicity to plants in some soils. For soils AC9 and RS there was no response from soybean plants to liming and no expressive manifestation of Al toxicity in them. In the PE, BR and $\mathrm{CB}$ soils the $1 \mathrm{~mol} \mathrm{~L}^{-1} \mathrm{KCl}$ was effective in the estimation of exchangeable $\mathrm{Al}$ and its toxic potential. The $\mathrm{CaCl}_{2}$ $0.01 \mathrm{~mol} \mathrm{~L}^{-1}$ was the extractor that best identified the toxic potential of $\mathrm{Al}$ in the evaluated soils.
\end{abstract}

Additional keywords: amorphous Al polymers; exchangeable aluminum; extraction methods; extractors. 


\section{Introdução}

Os solos brasileiros, em sua maioria, são muito intemperizados e ácidos, geralmente com teores de $\mathrm{Al}$ trocável $\left(\mathrm{Al}^{3+}\right)$ tóxicos às plantas (Miguel et al., 2010). Neste sentido, as espécies químicas consideradas mais tóxicas são: $\mathrm{Al}^{3+}, \mathrm{AlOH}^{2+} \mathrm{e}$ $\mathrm{Al}(\mathrm{OH})_{2}{ }^{+}$, e as não tóxicas são aquelas complexadas com ligantes orgânicos e inorgânicas na solução do solo (Hernández-Soriano, 2012; Spera et al., 2014; Rutkowska et al., 2015; Cunha et al. (2018a, b). As quantidades de Al trocável podem variar para cada tipo de solo, em função de sua composição química e mineralógica, do teor de matéria orgânica (MO) e do estágio de intemperização (Tandzi et al., 2018). O Al trocável é tradicionalmente quantificado com uma solução neutra de $\mathrm{KCl} 1 \mathrm{~mol} \mathrm{~L}^{-1}$, o qual doravante será denominado de $\mathrm{Al}-\mathrm{KCl}$. Em vários solos ácidos brasileiros com elevados teores de $\mathrm{Al}-\mathrm{KCl}$, no entanto, o $\mathrm{Al}^{3+}$ extraído com essa solução parece não indicar somente as frações trocáveis do elemento (Bernini et al. 2013; Cunha et al. 2014; 2015; Caballero et al., 2015), pois as plantas não respondem ou apresentam pouca resposta à calagem. Em muitos casos, as altas doses de calcário recomendadas para a correção da acidez por diferentes métodos de recomendação de calcário podem estar inativando espécies de Al que não são tóxicas, pois há pouco ou nenhum ganho de produtividade das culturas pela calagem, o que pode representar investimentos desnecessários (Cunha et al., 2018 a, b)..

Em vários solos ácidos brasileiros (Latossolos, Argissolos, Nitossolos e Cambissolos), principalmente naqueles com esmectitas, a estimativa do Al trocável pelo $\mathrm{KCl} 1 \mathrm{~mol} \mathrm{~L}^{-1}$ está sendo vista com cautela, pois apresentam reação ácida e elevados teores de $\mathrm{Al}^{3+}$, $\mathrm{Ca}^{2+}$ e $\mathrm{Mg}^{2+}$ trocáveis, que os tornam diferentes dos demais solos ácidos brasileiros (Bernini et al., 2013; Fontana et al., 2017). Apesar de o Al-KCl muitas vezes situar-se acima de $10 \mathrm{cmol}_{\mathrm{c}} \mathrm{kg}^{-1}$, o Al frequentemente não exerce efeitos tóxicos, mesmo para plantas sensíveis (Wadt, 2002; Araújo et al., 2004). Também tem sido observado que, em solos alíticos e alumínicos fortemente tamponados do extremo Sul do Brasil e em solos ácidos com argila de atividade mais alta de áreas úmidas das regiões Nordeste e Sul do Brasil, os elevados teores de $\mathrm{Al}-\mathrm{KCl}$ parecem não representar de forma adequada o Al trocável do solo (Teske et al., 2013; Cunha et al., 2014; 2015).

Além do emprego do $\mathrm{KCl}$ como extrator do $\mathrm{Al}$ "trocável", alguns países, como o Canadá e a Nova Zelândia, por exemplo, utilizam como extrator das frações de Al mais fracamente adsorvidas e potencialmente tóxicas às plantas a solução de $\mathrm{CaCl}_{2}$ 0,02 ou $0,01 \mathrm{~mol} \mathrm{~L}^{-1}$, cujas baixas concentrações simulariam melhor as condições de equilíbrio do Al na solução dos solos (Shuman, 1990; Houba et al., 2000). Esta solução extrai menores quantidades de Al do que o sal de $\mathrm{KCl}$, sendo necessário, neste caso, calibrar o método para a definição dos níveis considerados tóxicos para as principais culturas.

O método mais utilizado para a quantificação das frações de baixa cristalinidade e amorfas de compostos de Fe e de Al é o de Tamm modificado (Schwertmann, 1973), que utiliza como extrator a solução de oxalato de amônio a pH 3 (Schwertmann, 1964; McKeague \& Day, 1966). O método, entretanto, não é totalmente seletivo, podendo também extrair o Al ligado à matéria orgânica (Al-MO), além do $\mathrm{Al}$ adsorvido eletrostaticamente (García-Rodeja et al., 2004; Auxtero et al., 2012; Cunha et al., 2014; 2015). O Al extraído pelo oxalato de amônio $0,2 \mathrm{~mol} L$ ${ }^{1}$ provém principalmente da dissolução de compostos de $\mathrm{Fe}$ e de Al inorgânicos de baixa cristalinidade e uma pequena fração do Al da gibbsita (García-Rodeja et al., 2004; Varadachari et al., 2006) e de parte dos polímeros inorgânicos de hidroxi-Al entre camadas de argilominerais silicatados 2:1 (García-Rodeja et al., 2004).

Embora a interpretação dos resultados deva ser realizada com cautela, o uso do fracionamento químico do $\mathrm{Al}$, por meio de extrações químicas sequenciais (ES) e não sequenciais (ENS), pode ser útil na identificação de frações de Al que podem estar mais bem relacionadas com as respostas das plantas (Shuman, 1990; Coelho et al., 2010). Esses métodos foram propostos, neste estudo, para avaliar os sais e as concentrações salinas dos sais na dissolução de várias frações de $\mathrm{Al}$, pois a cada extração uma quantidade menor de Al trocável é deslocada, junto com uma quantidade maior de Al não trocável que pode estar contribuindo para o aumento dos teores do Al trocável.

A simples determinação dos teores do Al trocável do solo ou do Al total da solução do solo não é um indicador suficiente para avaliar a toxicidade desse elemento às plantas. Essa afirmação é amparada pelos estudos realizados por Hagvall et al. (2015), Rutkowska et al. (2015), De Conti et al., (2017) e Cunha et al. (2018 a, b), nos quais os autores avaliaram diferentes classes de solos com propriedades físicas, químicas e mineralógicas, e verificaram que solos com elevados teores de Al trocável, concomitantes com elevados teores de cátions básicos (principalmente $\mathrm{Ca}^{2+}$ e $\mathrm{Mg}^{2+}$ ) e de $\mathrm{P}$ tanto trocáveis como na solução, e de carbono orgânico dissolvido (COD)dos mesmos, a presença desse elemento, mesmo em quantidades elevadas em solução, não exerceu efeitos nocivos ao desenvolvimento das plantas testadas em seus respectivos estudos.Para isso, é necessária a quantificação das espécies químicas consideradas tóxicas, principalmente as espécies de Al lábil, como $\mathrm{Al}^{3+}, \mathrm{Al}(\mathrm{OH})^{2+}, \mathrm{Al}(\mathrm{OH}) 2^{+}$, assim como as espécies não tóxicas, sobretudo os complexos do Al com moléculas orgânicas e inorgânicas que alteram a proporção e a atividade tóxica do Al (Hernández-Soriano, 2012; Hagvall et al., 2015; Nolla et al., 2015). Em geral, a atividade do $\mathrm{Al}^{3+}$, ao invés das medidas das formas solúveis ou trocáveis, é o melhor indicador do potencial de toxicidade desse elemento em solos ácidos (Spera et al., 2014).

Considerando o exposto, a suscetibilidade da soja à acidez do solo e sua resposta à calagem, o 
estudo objetivou avaliar, por meio de ES e ENS, as possíveis frações de Al que podem contribuir para a superestimação do Al trocável, se as mesmas estão relacionadas com a toxicidade desse elemento às plantas de soja cultivadas em casa de vegetação, identificar a eficácia do $\mathrm{KCl} 1 \mathrm{~mol} \mathrm{~L}^{-1}$ em extrair somente as frações tóxicas do $\mathrm{Al}$ e o extrator que melhor estimou o potencial tóxico desse elemento às plantas de soja cultivadas em diferentes solos ácidos brasileiros.

\section{Material e métodos}

\section{Seleção dos solos}

O estudo foi realizado com amostras do horizonte subsuperficial (B) de cinco solos. Eles foram coletados em áreas nunca cultivadas, e a maioria tinha teores de $\mathrm{Al}-\mathrm{KCl}$ maior que $4 \mathrm{cmolc} \mathrm{kg}^{-1}$. Foram utilizadas amostras do horizonte $\mathrm{B}$, principalmente por apresentarem teores mais elevados do elemento e pelos menores teores de $\mathrm{MO}$ nesse horizonte, em relação ao horizonte superficial, pois a $\mathrm{MO}$ poderia influenciar nos resultados pela formação de complexos orgânicos com $0 \mathrm{Al}$. Com base nas diferenças mineralógicas e químicas, os solos foram distribuídos em três grupos: esmectíticos com elevados teores de $\mathrm{Al}^{3+}, \mathrm{Ca}^{2+}$ e $\mathrm{Mg}^{2+}$ trocáveis, representados pelas amostras AC9 (PVAal), proveniente do Estado do Acre, e Rosário do Sul (RS) (PBACal)], proveniente do Rio Grande do Sul; esmectíticos com caulinita, contendo elevados teores de Al e baixos teores de $\mathrm{Ca}^{2+}$ e $\mathrm{Mg}^{2+}$ trocáveis, cujos representantes são o PE (PVAal), proveniente do Estado de Pernambuco, e o BR (CHal), proveniente de Santa Catarina. Utilizou-se ainda de um solo catarinense, o CB (NBd), que foi utilizado como referência, por ser mais intemperizado, com mineralogia essencialmente caulinítica, e com menores teores de $\mathrm{Al}-\mathrm{KCl}, \mathrm{Ca}^{2+}$ e $\mathrm{Mg}^{2+}$ trocáveis que os demais.

Tabela1 - Classificação e atributos químicos dos perfis de solos coletados em diferentes regiões brasileiras antes da incubação dos mesmos e implantação dos experimentos em casa de vegetação. Classification and chemical attributes of soil profiles collected in different Brazilian regions before incubation of soils and implantation of greenhouse experiments.

\begin{tabular}{|c|c|c|c|c|c|c|c|c|}
\hline (1) Solo & Fonte & (2) $\mathrm{H}$ & $\begin{array}{l}\text { (3) Prof. } \\
\text { (cm) }\end{array}$ & Classificação & (4) Simbol. & $\mathrm{ph}$ & KCl & $\begin{array}{c}\mathrm{H}+\mathrm{Al} \\
\left(\mathrm{cmol}_{c} \mathrm{~kg}^{-1}\right)\end{array}$ \\
\hline AC9 & $\begin{array}{l}\text { Embrapa (2013a) } \\
\text { Cunha et al. (2018a) }\end{array}$ & $\mathrm{Bt}_{2}$ & 60-102 & $\begin{array}{l}\text { Argissolo Vermelho-Amarelo } \\
\text { Alítico plíntico }\end{array}$ & PVAal & 5,42 & 3,60 & 14,73 \\
\hline PE & Embrapa (2011a) & $\mathrm{Bt}_{2}$ & $55-105$ & $\begin{array}{l}\text { Argissolo Vermelho-Amarelo } \\
\text { Alítico típico }\end{array}$ & PVAal & 5,03 & 3,80 & 18,43 \\
\hline RS & Cunha et al. (2018a) & $\mathrm{Bt}_{3}$ & $65-80$ & $\begin{array}{l}\text { Argissolo Bruno-Acinzentado } \\
\text { Alítico típico }\end{array}$ & PBACal & 5,01 & 3,80 & 8,80 \\
\hline BR & Cunha et al. (2018a) & $\mathrm{Bi}$ & $60-90$ & $\begin{array}{l}\text { Cambissolo Húmico Alítico } \\
\text { típico }\end{array}$ & CHal & 4,82 & 3,86 & 9,87 \\
\hline $\mathrm{CB}$ & Cunha et al. (2018a) & $\mathrm{Bw}_{3}$ & $215-275^{+}$ & Nitossolo Bruno & NBd & 4,74 & 4,10 & 6,53 \\
\hline
\end{tabular}

(1) AC9: coletado no Acre, Perfil 9; PE: coletado em Pernambuco; RS: coletado no Rio Grande do Sul; BR: coletado em Bom Retiro-SC; CB; coletado em Curitibanos-SC; ${ }^{(2)}$ Horizontes coletados; ${ }^{(3)}$ Camada de coleta dos solos; ${ }^{(4)}$ Classificação de acordo com o Sistema Brasileiro de Classificação de Solos (Embrapa, 2013b). ${ }^{(1)}$ AC9: collected in Acre, Profile 9; PE: collected in Pernambuco; RS: collected in Rio Grande do Sul; BR: collected in Bom Retiro, SC; CB; collected in Curitibanos, SC; (2) Horizons collected; (3) Soil collection layer; (4) Classification according to the Brazilian Soil Classification System (Embrapa, 2013b).

As amostras de solo foram coletadas nos mesmos locais onde já haviam sido previamente descritos os respectivos perfis completos, cujos resultados já estão publicados (Tabela 1). As características mineralógicas desses solos são: no AC9, predomina esmectita (88\%), com baixas quantidades de interestratificados caulinita-esmectita $(6 \%)$ e de interestratificados mica-ilita $(6 \%)$; no PE, predomina esmectita (60\%) com quantidades relativamente altas de caulinita $(40 \%)$; no RS, predomina esmectita com baixas quantidades de ilita e caulinita; no BR, predomina caulinita $(51 \%)$, com quantidades relativamente altas de esmectita e vermiculita com polímeros de hidroxi entre camadas (47\%) (EHE e VHE, respectivamente) e baixa quantidade de interestratificados mica-ilita (2\%); e no CB, predomina caulinita (94\%), com $6 \%$ de EHE.
Maiores detalhes sobre os mesmos podem ser verificados em Cunha et al. (2014).

Após a coleta, as amostras de solo foram secas ao ar em casa de vegetação (CV), destorroadas, moídas e passadas em peneira de malha com $4 \mathrm{~mm}$ e, em seguida, foram incubadas separadamente. Para as análises químicas, utilizou-se de amostras peneiradas em malha de $2 \mathrm{~mm}$.

\section{Análises químicas e físicas antes da incubação dos solos com calcário}

As amostras de solo foram secas ao ar, em casa de vegetação, destorroadas, moídas e passadas em peneira com malha de $4 \mathrm{~mm}$ e, em seguida, foram incubadas separadamente. Para as análises químicas, utilizou-se de amostras passadas em peneira com malha de $2 \mathrm{~mm}$. 
Após o processamento das amostras, foi determinado o $\mathrm{pH}$ em água e em KCl $1,0 \mathrm{~mol} \mathrm{~L}^{-1}$, por potenciometria, na relação solo:solução de 1:2,5, o $\mathrm{H}+\mathrm{Al}$, por titulometria de neutralização, após extração com acetato de cálcio tamponado a pH 7 (Embrapa, 2011b), e a capacidade de retenção de água no solo (CRAS), esta segundo o método descrito na Embrapa (2011b), determinada em mesa de tensão, após emprego de uma tensão equivalente a uma coluna d'água de $100 \mathrm{~cm}(1 \mathrm{kPa})$ sobre a amostra saturada. As análises químicas foram realizadas com três repetições, e os resultados estão apresentados na Tabela 1.

\section{Incubação dos solos com calcário}

Os tratamentos consistiram na aplicação de quatro doses de calcário dolomítico (PRNT $=90 \%$, $\mathrm{CaO}=29 \%, \mathrm{MgO}=19 \%$, granulometria = filler; após o peneiramento em malha de $0,25 \mathrm{~mm}$ (Tedesco et al., 1995) em cada solo, corrigidas para $100 \%$ de Poder Relativo de Neutralização Total, que foram equivalentes ao necessário para neutralizar $0 ; 0,25$; 0,50 e 1,00 vez os teores de $\mathrm{H}+\mathrm{Al}$ (as doses de calcário para cada solo e tratamento foram calculadas de acordo com os resultados obtidos do $\mathrm{H}+\mathrm{Al}$ de cada solo, indicados na Tabela 1). Cada tratamento teve quatro repetições, e as doses foram aplicadas e homogeneizadas em amostras de $20 \mathrm{~kg}$ de solo (base seca). Em seguida, água destilada foi aplicada para elevar a umidade até $80 \%$ da CRAS. Posteriormente, as amostras foram adicionadas em sacos plásticos de 100 L. Em resumo, os sacos plásticos (protegidos por um saco de ráfia), após a adição de cada solo, das doses de calcário e da água destilada (80\% CRAS) foram fechados. A cada 15 dias, o conjunto (solo + sacos plásticos) foi pesado, a fim de avaliar se houve ou não perda de umidade do mesmo. Em seguida, foram abertos tanto para a homogeneização como para a oxigenação das amostras e, quando necessário, para a reposição da umidade perdida. Esta etapa foi realizada a cada 15 dias, e as amostras foram incubadas durante 98 dias até à estabilização dos valores de $\mathrm{pH}$.

\section{Cultivo de soja, análises químicas de solo e tecido vegetal e métodos de extração de alumínio}

Depois da incubação, as amostras de solo foram novamente passadas em peneiras com malha de $4 \mathrm{~mm}$, e os $20 \mathrm{~kg}$ de cada tratamento, que constituíam as quatro repetições, foram fertilizados com N, P e K a partir, respectivamente, do uso de ureia, superfosfato triplo e cloreto de potássio. Para o cultivo de soja, aplicaram-se: $1,08 \mathrm{~g} \mathrm{~kg}^{-1}$ de $\mathrm{N}$, $2,48 \mathrm{~g} \mathrm{~kg}^{-1}$ de $\mathrm{P}_{2} \mathrm{O}_{5}$ e $0,99 \mathrm{~g} \mathrm{~kg}^{-1}$ de $\mathrm{K}_{2} \mathrm{O}$.

As adubações com N, P e $\mathrm{K}$ foram as preconizadas pela Comissão de Química e Fertilidade do Solo para os Estados do Rio Grande do Sul e de Santa Catarina (CQFS-RS/SC, 2004), para a cultura da soja, tendo por base os resultados dos trabalhos já publicados (Tabela 1). A dose de $\mathrm{N}$ foi adicionada de uma só vez. As fontes de N, P e K foram aplicadas e misturadas nos solos após o período de incubação dos mesmos. Os cálculos de adubação para a soja visaram à produtividade de $3 \mathrm{t} \mathrm{ha}^{-1}$ de grãos.

Depois da incubação e da fertilização dos solos, os experimentos foram desenvolvidos sem casa de vegetação, em vasos de $8 \mathrm{~L}$, com $5 \mathrm{~kg}$ de solo (base seca) cada, durante 60 dias, no ano de 2015. O delineamento experimental foi em blocos ao acaso, organizado em esquema fatorial " $4 \times 5$ ", quatro doses de calcário $(0 ; 0,25 ; 0,5$ e 1,00$)$ e cinco tipos de solo, com quatro repetições para cada tratamento, dispostos em mesas, formando blocos.

Em cada vaso, foram semeadas, sem prégerminação, sete sementes e mantidas apenas três plantas após o desbaste realizado aos 20 dias após a emergência. Os solos foram mantidos com umidade próxima a $80 \%$ da CRAS, a partir de pesagens diárias dos vasos e reposição da umidade com água deionizada. As massas correspondentes ao crescimento das plantas de cada cultivo, em cada unidade experimental e tratamento, foram descontadas para a reposição da água.As plantas de soja foram coletadas no estádio fenológico de florescimento pleno. Após o raleio, foram mantidas três plantas por vaso.

Após o término do experimento, a parte aérea (PA) e as raízes foram coletadas rente ao solo e secas em estufa de circulação forçada, a $65-70^{\circ} \mathrm{C}$, até peso constante, quando, após a pesagem, foi obtida a matéria seca da parte aérea (MSPA). As raízes foram separadas dos solos, usando-se uma peneira de $2 \mathrm{~mm}$. Na sequência, elas foram lavadas em água corrente para a retirada das frações mais grosseiras do solo e secas em estufa de circulação forçada, na temperatura anteriormente citada, por 24 h. Após isso, foram lavadas novamente em água corrente para a retirada das partículas mais finas de solo. Em seguida, foram secas novamente e, com a pesagem das três raízes de cada unidade experimental, foi obtida a matéria seca de raízes (MSR). Com a soma da MSPA com a MSR foi obtida a matéria seca total (MST), produzida pelas plantas. Neste estudo, serão apresentados somente os resultados obtidos da MST.O comprimento do sistema radicular (CSR) foi obtido pelo sistema de varredura Winrhizo Pro - 2009 (Reagent Instruments Canada Inc.), com o escâner Epson Expression 10000 XL. Maiores detalhes podem ser verificados em Cunha (2017).

Depois da separação solo-raiz, coletaram-se aproximadamente $140 \mathrm{~g}$ de solo úmido de cada vaso, sendo colocados em recipiente de isopor contendo gelo e, em seguida, foram armazenados em ultrafreezer a $-80^{\circ} \mathrm{C}$ até à realização das análises químicas, tanto do solo como da solução. A ES do Al foi feita utilizando-se quatro extratores com diferentes concentrações e $\mathrm{pH}$, na seguinte ordem: 1) $\mathrm{CaCl}_{2}$ $0,01 \mathrm{~mol} \mathrm{~L}^{-1}$; 2) $\mathrm{KCl} 0,1 \mathrm{~mol} \mathrm{~L}^{-1}$, 3) $\mathrm{KCl} 1 \mathrm{~mol} \mathrm{~L}^{-1} \mathrm{e}$ 4) oxalato de amônio $0,2 \mathrm{~mol} \mathrm{~L}^{-1}$. A ENS foi feita utilizando-se somente das soluções de $\mathrm{KCl} 0,1 \mathrm{~mol} \mathrm{~L}^{-1}$, 
$\mathrm{KCl} 1 \mathrm{~mol} \mathrm{~L}^{-1}$ e oxalato de amônio $0,2 \mathrm{~mol} \mathrm{~L}^{-1}$, ambas na relação solo:solução de 1:10.

Os extratos de $\mathrm{CaCl}_{2} 0,01 \mathrm{~mol} \mathrm{~L}^{-1}, \mathrm{KCl} \mathrm{0,1} \mathrm{e}$ $1 \mathrm{~mol} \mathrm{~L}^{-1}$, para a determinação do $\mathrm{Al}$ extraído pelo método da ES foram obtidos pesando-se $4 \mathrm{~g}$ de TFSA em tubos de polietileno (Falcon) de $50 \mathrm{~mL}$, adicionando-se $40 \mathrm{~mL}$ de cada solução, sequencialmente. Na primeira extração, adicionaram-se $40 \mathrm{~mL}$ da solução de $\mathrm{CaCl}_{2}$ 0,01 mol L-1 aos tubos que foram agitados a $120 \mathrm{rpm}$, por $30 \mathrm{~min}$, em agitador horizontal, e centrifugados a $2.000 \mathrm{rpm}$, por $10 \mathrm{~min}$, com a leitura imediata do $\mathrm{pH}$ dos extratos. De cada amostra, foram retirados, respectivamente, 20 e $10 \mathrm{~mL}$ para a quantificação do Al por titulação com $\mathrm{NaOH}$ $0,02 \mathrm{~mol} \mathrm{~L}^{-1}$ e por espectrofotometria de absorção atômica (EAA) de alta resolução (Contraa 700). Em seguida, o excesso (sobrenadante claro) foi descartado e sobre o resíduo de solo foram adicionados $40 \mathrm{~mL}$ do extrator $\mathrm{KCl} 0,1 \mathrm{~mol} \mathrm{~L}^{-1}$, realizando-se 0 mesmo procedimento para a obtenção do extrato mencionado anteriormente e assim, sucessivamente, para os demais extratores. Para a obtenção do extrato de oxalato de amônio $0,2 \mathrm{~mol} \mathrm{~L}^{-1}$, foi realizado 0 mesmo procedimento mencionado anteriormente, porém com tempo de agitação maior, $4 \mathrm{~h}$ no escuro. A quantificação do Al extraído por esse extrator foi realizada somente por EAA, após a retirada de $10 \mathrm{~mL}$ do extrato. Procedimento similar foi realizado para a obtenção dos extratos para a ENS do Al nos solos, porém com uma única extração. $O$ método para a obtenção dos extratos de $\mathrm{KCl}$ e de oxalato de amônio foi adaptado de Embrapa (2011b) e McKeague \& Day (1966), por Cunha et al. (2015).

$\mathrm{O} \mathrm{Ca}^{2+}$ e o $\mathrm{Mg}^{2+}$ foram quantificados por EAA após a ENS com o KCl 0,1 e $1 \mathrm{~mol} \mathrm{~L}^{-1}$ nos mesmos extratos que o $\mathrm{Al}$ foi extraído, segundo o método descrito em Tedesco et al. (1995).

A determinação do valor de $\mathrm{pH}$ em água e em $\mathrm{CaCl}_{2} \quad 0,01 \mathrm{~mol} \mathrm{~L}^{-1}$ foi realizada na relação solo:solução de 1:2,5 após o término do experimento.

\section{Análise da solução do solo}

Para a simulação da solução do solo, foi obtido um extrato na relação solo:solução 1:1, por meio da pesagem de $20 \mathrm{~g}$ de TFSA e sua mistura com $20 \mathrm{~mL}$ de água ultrapura, em tubos de polietileno (Falcon) de $50 \mathrm{~mL}$. As amostras foram agitadas em aparelho horizontal, por $15 \mathrm{~min}$, a $150 \mathrm{rpm}$, seguido de uma hora em repouso. Em seguida, foram agitadas por mais cinco minutos e centrifugadas a $2.000 \mathrm{rpm}$, por 30 minutos. Na sequência, foram medidos imediatamente o $\mathrm{pH}$ e a condutividade elétrica (CE), e determinada a concentração $\mathrm{Ca}^{2+}, \mathrm{Mg}^{2+}, \mathrm{K}^{+}, \mathrm{Al}^{3+}$, $\mathrm{SO}_{4}{ }^{2-}, \mathrm{Cl}^{-}, \mathrm{NO}_{3}{ }^{-}, \mathrm{PO}_{4}{ }^{3-}$ e $\mathrm{COD}$. A especiação química da solução dos solos foi estimada pelo programa computacional Visual Minteq (para Windows) versão 3.1, baseado no programa Minteq A2 versão 4.0 (Gustafsson, 2016). Maiores detalhes podem ser verificados em Cunha et al. (2018a, b).
No geral, esses métodos de extração (ES e ENS) foram selecionados com o intuito de identificar o efeito da concentração salina e do sal sobre as possíveis frações de $\mathrm{Al}$, que podem estar contribuindo para a superestimação do Al trocável, correlacioná-los entre si e com o somatório da atividade das espécies tóxicas do $\mathrm{Al}$ (A乏FTAl) na solução do solo, estimada a partir dos íons solúveis em um extrato, na relação solo:solução de 1:1.

\section{Análise estatística}

Os dados relacionando os valores de $\mathrm{pH}$ nos diferentes extratores, do CSR, a produção de MST e os teores de Al extraídos com os diferentes extratores em função das doses de calcário aplicadas nos solos, foram submetidos à análise de variância (teste $\mathrm{F}$ ) com a utilização do software SISVAR 5.6 (Ferreira, 2014). Quando houve efeito significativo, 0 teste de comparações múltiplas de Tukey foi aplicado ao fator "tipos de solo" (incluindo o desdobramento dos tipos de solo em cada uma das doses de calcário). O teste de regressão foi aplicado ao fator "doses de calcário" (incluindo o desdobramento das doses de calcário em cada um dos tipos de solo), ambos a $5 \%$ de probabilidade de erro.

\section{Resultados e discussão}

\section{Valores de pH em água, após a extração química sequencial (ES) e normal (ENS)}

Os valores de $\mathrm{pH}$ em água (Figura 1a), em $\mathrm{CaCl}_{2}$ 0,01 $\mathrm{mol} \mathrm{L}^{-1}(1: 2,5)$, do $\mathrm{pH}$ em CaCl $2,01 \mathrm{~mol} \mathrm{~L}^{-1}$, em $\mathrm{KCl} 0,1$ e $1 \mathrm{~mol} \mathrm{~L}^{-1} \mathrm{e}$ em oxalato de amônio $0,2 \mathrm{~mol} \mathrm{~L}^{-1}$, após a extração sequencial (pH-ES), e nos dois últimos, após extração não sequencial (pH-ENS), todos na relação solo:solução de 1:10, apresentaram comportamento linear crescente e alta correlação, em função da calagem, em todos os solos (Figura 1). Devido a essa similaridade, são mostrados somente os resultados referentes ao $\mathrm{pH}$-ENS.

Os valores de $\mathrm{pH}$ em água foram sempre maiores do que os determinados nos demais métodos (pH-ES e pH-ENS) e extratores utilizados, observando-se menor inclinação das retas em relação aos demais métodos. Nos tratamentos sem calcário, o pH em água variou de 4,63 (PE) a 4,91 (AC9) e, com a calagem, o pH aumentou significativamente (variando na dose máxima de 5,61 no AC9 a 6,21 noCB) (Figura 1a).

Os valores de $\mathrm{pH}$-ES nos extratos de $\mathrm{CaCl}_{2}$ $0,01 \mathrm{~mol} \mathrm{~L}^{-1}$ (pH $\mathrm{pHacl}_{2 \mathrm{ES}}$ ) (relação solo:solução 1:10), na média das doses de calcário de cada solo, foram maiores nos solos $C B$ e RS, e similares nos solos

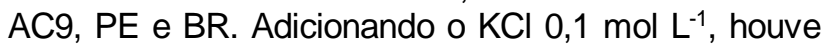
ligeira redução nos valores de $\mathrm{pH}$ nessa solução $\left(\mathrm{pH} \mathrm{KCl}_{0,1} \mathrm{ES}\right)$, sendo inferiores aos determinados em água (Figura 1a), mais elevados do que em $\mathrm{CaCl}_{2}$ $0,01 \mathrm{~mol} \mathrm{~L}^{-1}$ na relação $1: 10$ e mais baixos na relação 1:2,5, utilizando esse mesmo extrator. Com a adição do $\mathrm{KCl} 1 \mathrm{~mol} \mathrm{~L}^{-1}$, houve o aumento do $\mathrm{pH}$ medido 
nessa solução ( $\mathrm{pH}_{\mathrm{KCl1}} \mathrm{ES}$ ) em todos os solos, porém sempre mais baixos do que os medidos em água (dados não apresentados).

Entretanto, houve similaridade, principalmente nos tratamentos sem calcário, entre $0 \mathrm{pH}_{\mathrm{kCl}, 1,1} \mathrm{ES}$ (dados não apresentados) com o pHkcl1 ENS (Figura 1b). Isso pode ter ocorrido pelo aumento de íons $\mathrm{H}^{+}$na solução, provenientes da hidrólise das frações não trocáveis de $\mathrm{Al}$, que foram dissolvidas com o aumento da concentração salina, refletindo na diminuição do pH (Zambrosi et al., 2007; Ebeling et al., 2008; Campos et al., 2014; Cunha et al., 2015).

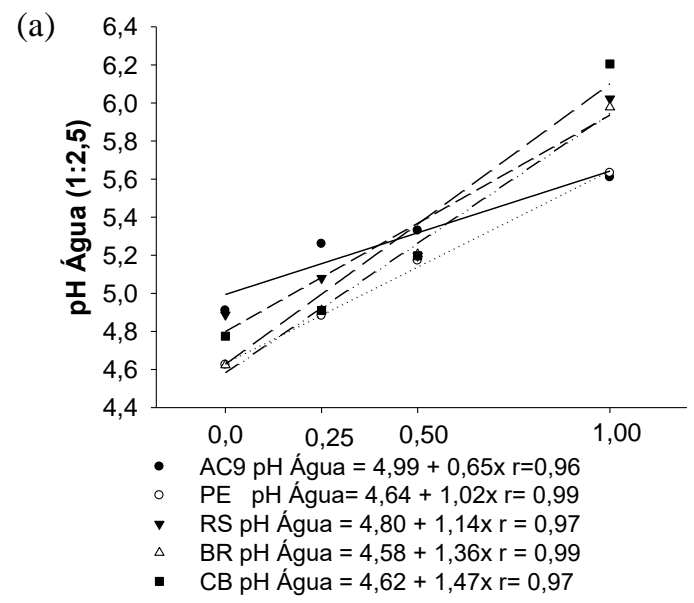

(c)

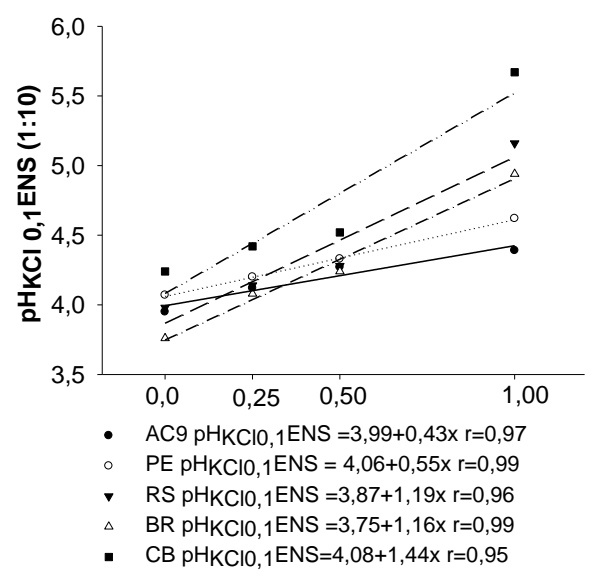

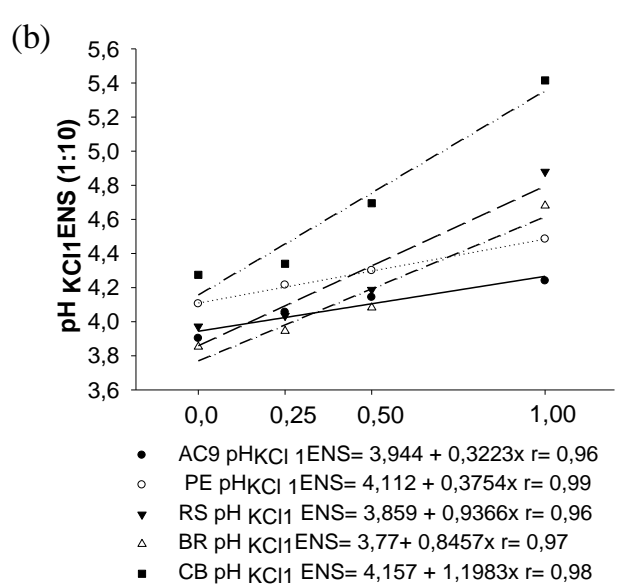

(d)

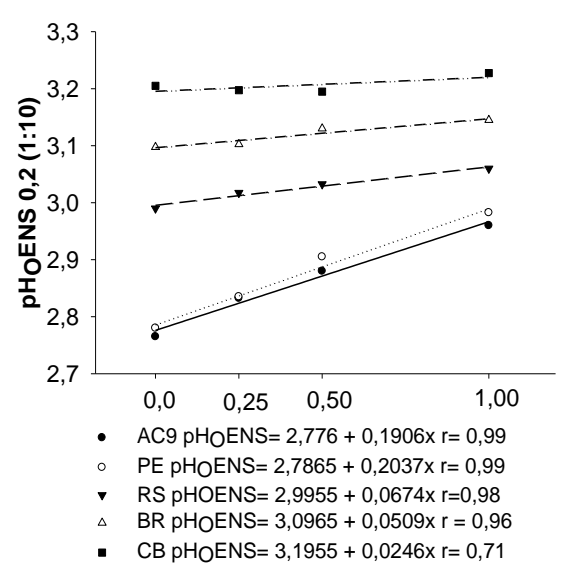

Doses de Calcário x $\mathrm{H}+\mathrm{Al}\left(\mathrm{t} \mathrm{ha}{ }^{-1}\right.$ )

Figura 1 - Relação entre o pH: a)em água; b) em $\mathrm{KCl} 1 \mathrm{~mol} \mathrm{~L}^{-1}$, c) 0,1 $\mathrm{mol} \mathrm{L}^{-1}$, e d) em oxalato de amônio (pHoENS), em função das doses de calcário aplicadas nos solos do Acre (AC9), Pernambuco (PE), Rosário do Sul (RS), Bom Retiro (BR) e de Curitibanos (CB), após cultivo de soja, durante 60 dias, em casa de vegetação. Relationship between $\mathrm{pH}$ : a) in water, b) in $\left.\mathrm{KCl} 1 \mathrm{~mol} \mathrm{~L}^{-1}, c\right) 0.1 \mathrm{~mol} \mathrm{~L}^{-1}$ and d) in ammonium oxalate (pHoENS) in function of the limestone doses applied in the soils of Acre (AC9), Pernambuco (PE), Rosário do Sul (RS), Bom Retiro (BR) and Curitibanos (CB) after soybean cultivation for 60 days in a greenhouse.

Nos extratos do $\mathrm{CaCl}_{2}$ 0,01 $\mathrm{mol} \mathrm{L}^{-1}(1 ; 2,5)$, do $\mathrm{KCl} 1 \mathrm{~mol} \mathrm{~L}^{-1}(1: 10)$, ambos determinados pelo método da ENS, os valores de $\mathrm{pH}$ foram cerca de 0,2 a 0,8 unidades de $\mathrm{pH}$ mais baixos daqueles determinados em água, nos solos com e sem calcário. Quando comparados entre si, considerando todos os solos e as médias das doses de calcário aplicadas aos mesmos, nota-se alta correlação $(r=0,84)$ nos valores de $\mathrm{pH}$ medidos nesses extratos. Portanto, independentemente da concentração salina, do efeito da diluição ou do sal empregado, ambos mantiveram quantidades semelhantes de $\mathrm{H}^{+}$na solução, como verificado por Cunha et al. (2015), em estudo realizado com os mesmos solos, e Santos et al. (2017) em outras classes de solo. Apesar dessa similaridade, nota-se maior redução do pH $\mathrm{kcl}_{1} \mathrm{ENS}$, evidenciada pela maior inclinação das retas (Figura 1b). Essa redução ocorreu devido à dissolução de outras frações de Al, além da trocável, pela maior concentração salina, que aumenta a força iônica da solução, incrementando a hidrólise do Al (Inda et al., 2010; Bernini et al., 2013; Cunha et al.,2015).Isto não deve ter ocorrido na ES, em virtude da extração prévia de algumas dessas frações.

No extrato do oxalato de amônio $0,2 \mathrm{~mol} \mathrm{~L}^{-1}$, os valores de $\mathrm{pH}$ nos métodos ES (dados não mostrados) e ENS (Figura 1d) foram inferiores aos determinados em água e nos demais extratores, mantendo-se próximos do valor do tampão ( $\mathrm{pH}=3,0)$, com ligeiro aumento devido à calagem em todos os solos. 
Em geral, as médias dos pH's determinados entre os diferentes extratores e nas duas relações solo:solução (1:2,5 e 1:10) foram muito similares. O aumento da relação solo:solução não influenciou na medida do $\mathrm{pH}$ dos extratos, uma vez que a dissociação de $\mathrm{H}^{+}$pela fase sólida do solo continuou tamponando o pH (Almeida \& Ernani, 1996). Isto também pode estar relacionado com o tempo e com o modo de agitação das amostras, que poderiam estar promovendo o maior deslocamento do Al na solução por reações de troca, anulando ou minimizando o efeito da diluição (Cunha et al., 2015).

\section{Extração química sequencial e não sequencial do alumínio}

Apesar dos diferentes teores de Al quantificados pelos diferentes métodos de determinação (ES e ENS), os teores de Al apresentaram ajuste quadrático e alta correlação com as doses de calcário aplicadas aos solos, independentemente do método de quantificação (titulação; Tit ou EAA) (Figura 2).

Os teores de Al quantificados por titulação foram muito similares aos determinados por EAA e apresentaram alta correlação linear positiva $(r>0,97)$, independentemente do método de extração (dados não mostrados). A equação de regressão obtida para os dados de Al na ENS com a solução de $\mathrm{KCl} 1 \mathrm{~mol} \mathrm{~L}^{-1}$, pelos dois métodos de quantificação, por exemplo, foi: $\left[\mathrm{KCl}_{\text {EAA }}=(0,9681 \times \mathrm{KCl}\right.$ TiT $\left.)+0,1627, r=0,97\right]$. Resultados semelhantes foram obtidos por Boeira et al. (2004), Bernini et al. (2013), Cunha et al. (2015) e Campos et al. (2014).Este comportamento é comum, principalmente em solos com baixos teores de $\mathrm{MO}$ (Boeira et al., 2004), em que as quantidades de $\mathrm{H}^{+}$ provenientes da ionização dos ácidos orgânicos da MO pouco interferem no cálculo do Al trocável pela titulação (Coelho et al., 2010). Neste sentido, este estudo sugere que o Al extraído e quantificado por qualquer método, devido à alta correlação, poderia ser um bom indicador da presença do Al tóxico nos solos, mas não necessariamente isso significa que, tendo determinada quantidade de Al automaticamente indicará provável toxidez (índice de Al) desse elemento às plantas. Portanto, vale salientar que não é o teor de Al presente nos solos que é importante, sendo necessário buscar um indicador que leve em conta o Al extraído pelos métodos de extração utilizados neste estudo. Além disso, levar em consideração os teores dos cátions básicos, do $\mathrm{P}$ e da $\mathrm{m} \%$ do solo, a fim de avaliar se os elevados teores de Al extraídos principalmente pelo $\mathrm{KCl}$ poderão ou não causar uma provável toxicidade às plantas.

$\mathrm{Na}$ primeira $\mathrm{ES}, \mathrm{O} \mathrm{CaCl}_{2} 0,01 \mathrm{~mol} \mathrm{~L}^{-1}$ extraiu os menores teores de $\mathrm{Al}$ por titulação (Alcacl2ES) (Figura 2) e por EAA em todos os solos, quando comparado aos demais extratores, havendo alta similaridade dos valores pelos dois métodos de quantificação (dados não mostrados). Após a segunda $\mathrm{ES}$, com KCl 0,1 $\mathrm{mol} \mathrm{L}^{-1}$ (AlkClo,1ES), os teores de Al extraídos por essa solução e quantificados por titulação foram sempre mais elevados do que os da primeira extração, em todos os solos, exceto no solo $\mathrm{CB}$ (Figura 2). Na média de todos os solos, o $\mathrm{Al}_{\mathrm{KCl}, 1,1 \mathrm{ES}}$ foi 3 vezes maior do que o $\mathrm{Al}_{\mathrm{CaC} 120,01} \mathrm{ES}$, porém foi 2,8 vezes menor do que o determinado na extração

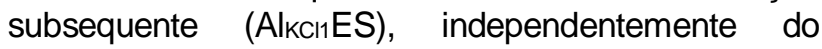
método de quantificação utilizado e da dose de calcário aplicada (Figura 2). Comportamento similar do Al foi obtido na ENS pela solução de $\mathrm{KCl} 0,1 \mathrm{~mol} \mathrm{~L}^{-1}$ (Alkcio, ENS) sendo, na média de todos os solos, cerca de 2,05 vezes menor do que os valores obtidos com o uso do $\mathrm{KCl} 1 \mathrm{~mol} \mathrm{~L}^{-1}$ (Figura 2).

Os menores teores de Al obtidos pela extração com CaCl $2 \quad 0,01 \mathrm{~mol} \mathrm{~L}^{-1}$ e com $\circ \mathrm{KCl}$ $0,1 \mathrm{~mol} \mathrm{~L}^{-1}$ em comparação aos do $\mathrm{KCl} 1 \mathrm{~mol} \mathrm{~L}^{-1}$, segundo Cunha et al. (2015), estão relacionados com a baixa concentração desses sais, que promovem menor hidrólise dos compostos de Al, o que poderia estar indicando mais realisticamente as frações do Al em equilíbrio mais imediato com o Al da solução do solo.

Os teores de AlkC11ES quantificados por titulação, conforme esperado, foram sempre inferiores aos obtidos pelo Alkc11ENS, uma vez que a parcela do Al mais fracamente retida pelos colóides já havia sido retirada pelas extrações anteriores com os sais de cloreto de cálcio e de potássio menos concentrados. Entretanto, foram sempre maiores do que o Al extraído pelos sais menos concentrados, principalmente nos tratamentos sem calcário (Figura 2). Apesar disso, a soma do Al das extrações sequenciais com $\mathrm{CaCl}_{2}, \mathrm{KCl}$ 0,1 e $\mathrm{KCl} 1 \mathrm{~mol} \mathrm{~L}^{-1}$ foi similar à do Al obtido com uma única extração com KCl $1 \mathrm{~mol} \mathrm{~L}^{-1}$ (Figuras 2a a 2e), independentemente do método de quantificação, mantendo alta correlação entre os dois valores (Tabela 2). A proximidade entre a soma do Ales com o AlENS sugere que 0 método da ES foi adequado para 0 conhecimento das diferentes frações do Al que podem estar contribuindo para a superestimação do $\mathrm{Al}$ trocável; porém, com as tecnologias e métodos de análise atualmente empregadas, é impraticável de ser utilizado em laboratórios de rotina pela demora na obtenção dos resultados.

Este comportamento fortalece a interpretação de que as frações do Al obtidas durante a extração sequencial com as três soluções removeram o elemento contido numa "matriz" ou "compartimento" similar. Estas podem ser tanto provenientes de frações de Al monomérico, adsorvido aos coloides por forças eletrostáticas, como também de frações de Al de formas poliméricas, ou complexadas pela $\mathrm{MO}$, ambas retidas com maior energia de ligação, porém solubilizadas pelo efeito dos sais. 
(a)

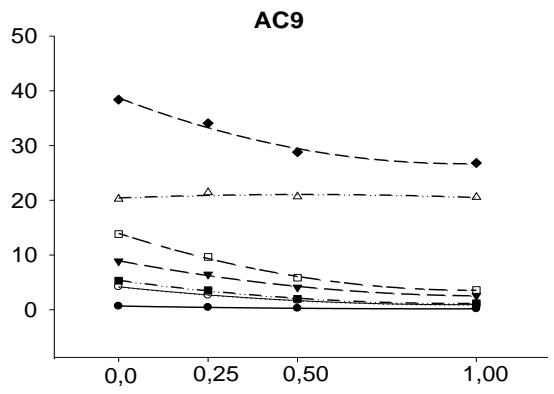

- $\quad \mathrm{Al}_{\mathrm{CaCl} 2} \mathrm{ESTit}=0,67-1,13 \mathrm{x}+0,64 \mathrm{x}^{2} \mathrm{r}=0,99$

- $\mathrm{Al}_{\mathrm{KCl}, 1}$ ESTit $=4,19-6,82 \mathrm{x}+3,56 \mathrm{x}^{2} \mathrm{r}=0,99$

- $\mathrm{Al}_{\mathrm{KCl} 1} \mathrm{ESTit}=8,94-12,34 \mathrm{x}+5,95 \mathrm{x}^{2} \mathrm{r}=0,99$

$\triangle \quad A l_{O E S E A A}=20,43+2,67 x-2,39 x^{2} r=0,61$

- $\quad \mathrm{Al}_{\mathrm{KCl} 0,1}$ ENSTit $=5,36-8,86 \mathrm{x}+4,66 \mathrm{x}^{2} \mathrm{r}=0,99$

- $\quad \mathrm{Al}_{\mathrm{KCl} 1}$ ENSTit $=13,94-20,08 \mathrm{x}+10,69 \mathrm{x}^{2} \mathrm{r}=0,99$

- $\quad$ AlOENSEAA $=38,09-25,0,8 x+13,09 x^{2} r=0,99$

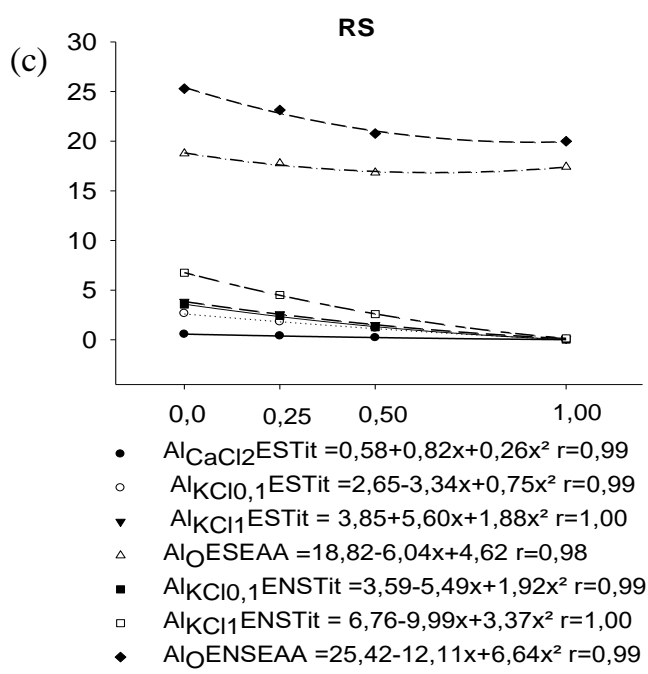

(b)

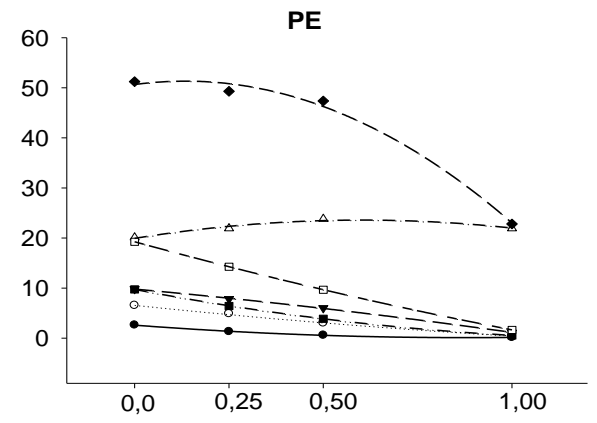

- $\quad \mathrm{Al}_{\mathrm{CaCl} 2} \mathrm{ESTit}=2,61-5,68 \mathrm{x}+3,23 \mathrm{x}^{2} \mathrm{r}=0,99$

- $\mathrm{Al}_{\mathrm{KCl} 0,1}$ ESTit $=6,63-7,82 \mathrm{x}+1,69 \mathrm{x}^{2} \mathrm{r}=0,99$

- $\mathrm{Al}_{\mathrm{KCl} 1}$ ESTit $=9,78-6,80 \mathrm{x}-1,85 \mathrm{x}^{2} \mathrm{r}=0,99$

$\triangle \quad \mathrm{Al}_{\mathrm{O}} \mathrm{ESEAA}=19,94-15,15 \mathrm{x}-10,12 \mathrm{x}^{2} \mathrm{r}=0,98$

- $\quad$ AlKCI0,1$_{1}$ ENSTit $=9,73-14,30 x+5,14 x^{2} r=1,00$

- $\quad$ AlKCl1 $_{\text {ENSTit }=19,24-20,68 x+3,09 x^{2} r=1,00}$

- $\quad \mathrm{Al}_{\mathrm{O}} \mathrm{ENSEAA}=60,55+10,03 \mathrm{x}-37,69 \mathrm{x}^{2} \mathrm{r}=0,99$

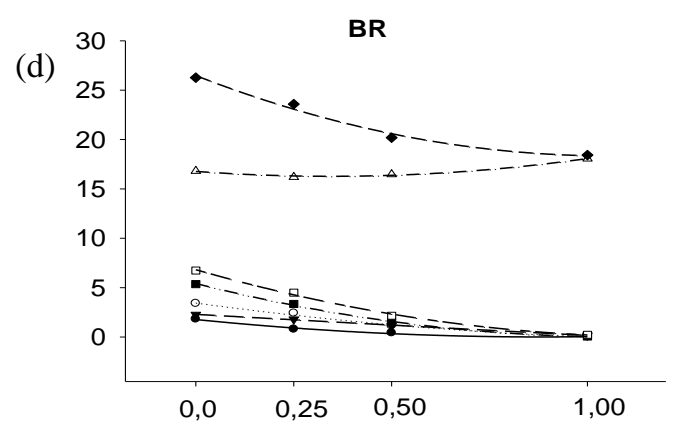

- $\quad \mathrm{Al}_{\mathrm{CaCl}}$ ESTit $=1,78-3,99 \mathrm{x}+2,26 \mathrm{x}^{2} \mathrm{r}=0,99$

- $A l_{K C I 0,1}$ ESTit $=3,48-5,40 x+1,99 x^{2} r=0,99$

- $A l_{\text {KCl1 }}$ ESTit $=2,29-2,22 x+0,09 x^{2} r=0,99$

$\triangle \quad \mathrm{Al}_{\mathrm{O}} \mathrm{ESEAA}=16,76-2,85 \mathrm{x}+4,16 \mathrm{x}^{2} \mathrm{r}=0,99$

- $A l K C l 0,1$ ENSTit $=5,41-9,97 x+4,60 x^{2} r=0,99$

- $\quad$ AlKCl1$_{1}$ ENSTit $=6,81-11,34 x+4,73 x^{2} r=0,99$

- $\quad$ AlOENSEAA $=26,47-15,43 x+7,33 x^{2} r=0,99$

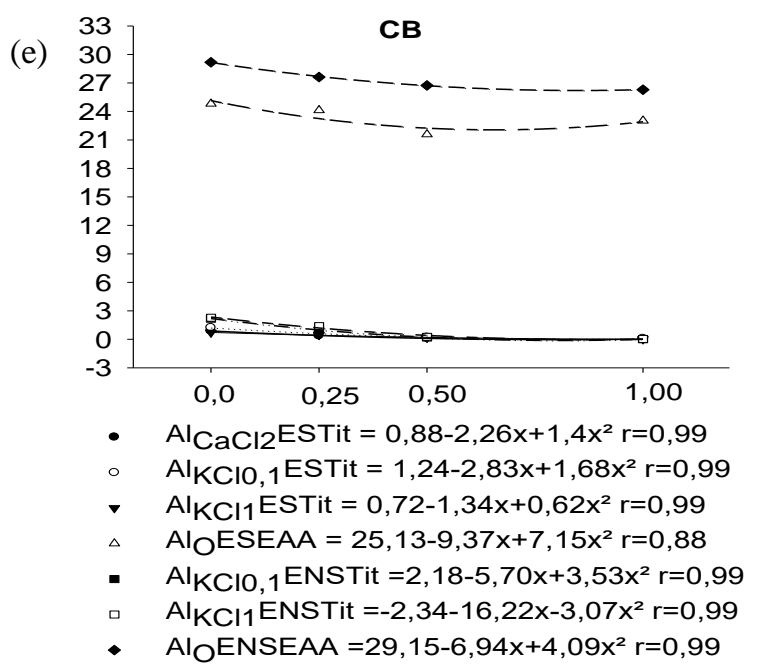

\section{Doses de Calcário $\times \mathrm{H}+\mathrm{Al}\left(\mathrm{t} \mathrm{ha}^{-1}\right)$}

Figura 2 - Relação entre o alumínio extraído pelos diferentes extratores e métodos de extração (ES e ENS) e diferentes métodos de quantificação (Tit; titulação e EAA; espectrofotometria de absorção atômica) em função das doses de calcário aplicadas nos solos do: a) Acre (AC9); b) Pernambuco (PE); c) Rosário do Sul (RS); d) Bom Retiro (BR), e e) Curitibanos (CB). Relation between the aluminum extracted by the different extractors and extraction Methods (ES and ENS), and different methods of quantification (Tit; titration and AAE; atomic absorption spectrophotometry), as a function of the limestone doses applied in the soils of: a) Acre (AC9); b) Pernambuco (PE); c) Rosário do Sul (RS); d) Bom Retiro (BR) and; e) Curitibanos (CB). 
A superestimação do Al-KCl ("trocável")estaria relacionada, segundo Cunha et al. (2014;2015), com a mineralogia diferenciada da fração argila desses solos e com a alta concentração salina da solução de $\mathrm{KCl} 1$ mol L-1, que pode estar dissolvendo não só as frações monoméricas de compostos de $\mathrm{Al}$, mas também parte de polímeros de Al inorgânicos de baixa cristalinidade e amorfas, de fases discretas e de polímeros de Al de entrecamadas de argilominerais $2: 1$, evidenciada pela alta correlação entre $0 \quad \mathrm{Al}-\mathrm{KCl}$ e 0 Alo. Essa superestimação do Al "trocável" pode induzir a um cálculo superestimado da saturação por alumínio (índice $\mathrm{m} \%$ ) podendo estar indicando uma eventual toxicidade de Al pelas plantas, sem que esta esteja sendo manifestada pelas mesmas (Cunha et al., 2018a,b). Entretanto, observa-se que não há diferença no comportamento das curvas e dos teores de $\mathrm{Al}-\mathrm{KCl}$ no solo SCCB (mais caulinítico), tanto na ES como na ENS (Figura 2e), demonstrando que, para solos mais intemperizados, o $\mathrm{KCl} 1 \mathrm{~mol} \mathrm{L^{-1 }}$ estimou de forma adequada o $\mathrm{Al}$ que está em equilíbrio mais imediato com o da solução do solo.

$\mathrm{Na}$ quarta ES, com oxalato de amônio, os teores de Alo foram muito mais elevados quando comparados aos demais extratores, principalmente nos solos AC9 (Figura 2a) PE (Figura 2b); sendo, na média de todos os solos e tratamentos, 33; 10 e 6,5 vezes maiorres que o $\mathrm{Al}_{\mathrm{CaCl} 2 \mathrm{ES},} \mathrm{O} \mathrm{Al}_{\mathrm{KCl}, 1,1} \mathrm{ES}$ e 0 AlkCl1 ES, respectivamente, e 1,4 vez menores do que Alo pelo método ENS, quantificado por espectrofotometria de absorção atômica (AloENSEAA) (Figuras $2 \mathrm{a}$ a 2e). No entanto, somando-se os teores de Al da ES obtidos com os quatro extratores, observou-se que os teores de Al quantificados foram muito similares aos obtidos por uma única extração com o oxalato (AloENSEAA) (Figuras $2 \mathrm{a}$ a $2 \mathrm{e}$ ), havendo alta correlação entre os métodos (Tabela 3, Soma ES $x$ Alo). Este comportamento indica que o sal de oxalato obtido na ENS extraiu, além do Al das frações amorfas ou de baixa cristalinidade, também o Al adsorvido e quantificado pelos demais sais.

O fato de a calagem não ter promovido variações expressivas nos teores de Al quantificados na última ES com o oxalato de amônio (AloES), em praticamente todos os solos (Figuras 2 a a $2 e$ ), demonstra que as frações do $\mathrm{Al}$ de baixa cristalinidade, remanescentes após a terceira extração, devem ser muito estáveis, não sendo neutralizadas pela calagem. Decorrente disso, poderse-ia interpretar que as frações de baixa cristalinidade de Al foram pouco afetadas pelos tratamentos, o que contraria a interpretação anterior de que o Al obtido pelo $\mathrm{KCl} 1 \mathrm{~mol} \mathrm{~L}^{-1}$ pode superestimar as frações trocáveis do elemento. Entretanto, é fato conhecido que a solução de oxalato de amônio não é totalmente seletiva, podendo incluir formas muito variadas de compostos orgânicos e inorgânicos, tais como Al-MO, polímeros inorgânicos amorfos discretos e formas destes polímeros presentes nas entrecamadas dos minerais de camada $2: 1$, além do próprio Al trocável (Cunha et al., 2014; 2015; Olatunji et al., 2015). Desse modo, frações de Al amorfas de maior estabilidade

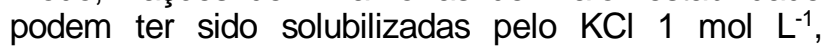

embora não tenham sido computadas no cálculo do Alo da ES, uma vez que já haviam sido solubilizadas e contabilizadas na extração anterior com o sal de $\mathrm{KCl}$.

\section{Relação entre os métodos de extração de Al}

Os valores de Al quantificados pelos diferentes extratores e métodos de extração e quantificação tiveram alta correlação com a A\&FTAl na solução do solo, na maioria dos solos avaliados (Tabela 2). Portanto, parece plausível a hipótese de que todos os extratores determinaram adequadamente o $\mathrm{Al}$ da solução do solo. Exceção ocorreu para o AloES, em que foram encontradas baixas correlações com alguns extratores e com a A EFTAl na solução do solo, principalmente nos solos AC9, BR e CB após a ES. Isso pode ter ocorrido, no caso do AloES, pela eliminação prévia de praticamente todas as frações do Al não diretamente associadas aos compostos de baixa cristalinidade ou "amorfos" do elemento, decorrentes da utilização prévia dos extratores $\mathrm{CaCl}_{2} \quad 0,01 \mathrm{~mol} \mathrm{~L}^{-1}, \mathrm{KCl} \mathrm{0,1} \mathrm{e}$ $1 \mathrm{~mol} \mathrm{~L}^{-1}$. Essa hipótese é, além do mais, reforçada pela elevada correlação obtida entre o AloENS (em que parte das frações mais lábeis do Al estavam ainda presentes na amostra) com os demais extratores e, sobretudo, com a alta correlação do AloENS com A乏FTAl na solução do solo, exceto para o solo BR (Tabela 2).

Os teores de Al obtidos pelo cloreto de cálcio $0,01 \mathrm{~mol} \mathrm{~L}^{-1}\left(\mathrm{Al}_{\mathrm{CaCl}}\right)$, apesar de esse sal ter extraído quantidades muito inferiores de $\mathrm{Al}$ do que pelos demais extratores, tiveram alta correlação linear com o Al extraído com os demais extratores, com exceção do AloES nos solos AC9 e BR, e muito alta com a A ¿्FTAl na solução (Tabela 2 ), com a produção de MST e com o CSR (dados não mostrados). Esses resultados são similares aos encontrados por Shuman (1990) e Houba et al. (2000), os quais relataram que o cloreto de cálcio, além de dissolver muito menos Al em relação aos sais neutros, é altamente correlacionado ao Al extraído na solução do solo, com a m\% e com crescimento e produção de plantas. Segundo Shuman et al. (1990), o método é muito eficaz para prever a toxicidade de Al às plantas, uma vez que é mais fácil de se obter o $\mathrm{Al}_{\mathrm{CaCl}}$ do que a $\mathrm{m} \%$ ou a atividade de $\mathrm{Al}^{3+}$ na solução do solo, requerendo apenas uma análise para a determinação do $\mathrm{Al}$, enquanto as outras requerem análises múltiplas.

Para o Alo, em virtude de se tratar de formas provavelmente de equilíbrio muito lento com o $\mathrm{Al}$ da solução, não era esperado que tivessem correlação com a A\&FTAl na solução do solo, com o $\mathrm{Al}_{\mathrm{CaCl} 2} \mathrm{ES}$ e com AlkClo,1 ENS (por terem valores muito inferiores de Al) (Tabela 2), com a produção de MST (r entre 0,86 e 0,99 ) e com o CSR ( $r$ entre 0,98 e 0,99). Esperava-se alta correlação com o $\mathrm{Al}-\mathrm{KCl}$ como verificado por Cunha et al. (2015) e, consequentemente, com a m\% do solo, tal como também ocorreu no presente estudo. No entanto, apesar dessas altas correlações, esse extrator não é adequado para indicar o potencial tóxico do Al às plantas, pois dissolve outras frações de Al além da trocável, sendo estas indisponíveis para as plantas na solução. 
Tabela 2 - Relação entre o Al extraído com diferentes extratores, métodos de extração e quantificação em amostras de cinco perfis de solos ácidos brasileiros. Relationship between Al extracted with different extractors, methods of extraction and quantification in samples of five profiles of Brazilian acid soils.

\begin{tabular}{|c|c|c|c|c|c|c|c|c|c|}
\hline \multirow{4}{*}{ (1) Solo } & \multirow{4}{*}{ (2) $\mathrm{Al}$ M.Extração } & \multicolumn{3}{|c|}{ Titulação } & (3) EAA & \multicolumn{2}{|c|}{ Titulação } & EAA & MINTEq \\
\hline & & \multicolumn{4}{|c|}{ 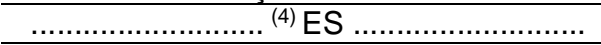 } & \multicolumn{4}{|c|}{$\ldots \ldots \ldots \ldots \ldots \ldots . .{ }^{(5)}$ ENS $\ldots \ldots \ldots \ldots \ldots \ldots \ldots$} \\
\hline & & ${ }^{(6)} \mathrm{Al}_{\mathrm{CaCl} 2}$ & (7) $\mathrm{Al}_{\mathrm{KCl}} 0,1$ & ${ }^{(8)} \mathrm{Al}_{\mathrm{KCl} 1}$ & (9) $\mathrm{Al}_{\mathrm{O}}$ & (10) $\mathrm{Al}_{\mathrm{KClO}, 1}$ & ${ }^{(11)} \mathrm{Al}_{\mathrm{KCl}}$ & ${ }^{(12)} \mathrm{Al}_{\mathrm{O}}$ & (13) $\mathrm{A} \Sigma \mathrm{FTAl}$ \\
\hline & & \multicolumn{8}{|c|}{$r$} \\
\hline \multirow{9}{*}{ AC9 } & $\mathrm{Al}_{\mathrm{CaCl} 2} \mathrm{ES}$ & - & 0,99 & 0,99 & 0,18 & 0,99 & 0,99 & 0,99 & 0,99 \\
\hline & $\mathrm{Al}_{\mathrm{KCl} 0,1} \mathrm{ES}$ & 0,99 & - & 0,99 & 0,21 & 0,99 & 0,99 & 0,98 & 0,95 \\
\hline & $\mathrm{Al}_{\mathrm{KCl} 11} \mathrm{ES}$ & 0,99 & 0,99 & - & 0,11 & 0,99 & 0,99 & 0,99 & 0,98 \\
\hline & Soma ES ${ }^{(14)}$ & - & - & - & 0,19 & 0,99 & 0,99 & 0,99 & 0,98 \\
\hline & $\mathrm{Al}_{\mathrm{OES}}$ & 0,18 & - & 0,21 & - & 0,15 & 0,99 & 0,11 & 0,01 \\
\hline & Soma ES ${ }^{(15)}$ & - & - & - & 0,14 & 0,99 & 0,98 & 0,99 & 0,99 \\
\hline & $\mathrm{Al}_{\mathrm{KCl}, 1,1} \mathrm{ENS}$ & - & - & - & - & - & 0,99 & - & 0,98 \\
\hline & $\mathrm{Al}_{\mathrm{KCl} 11} \mathrm{ENS}$ & - & - & - & - & 0,99 & - & 0,99 & 0,99 \\
\hline & $\mathrm{Al}_{\mathrm{O}} \mathrm{ENS}$ & 0,99 & 0,98 & 0,99 & 0,09 & 0,99 & 0,99 & - & 0,99 \\
\hline \multirow{9}{*}{ PE } & $\mathrm{Al}_{\mathrm{CaCl} 2} \mathrm{ES}$ & - & 0,97 & 0,90 & 0,76 & 0,90 & 0,94 & 0,72 & 0,90 \\
\hline & $\mathrm{Al}_{\mathrm{KCl} 0,1} \mathrm{ES}$ & - & - & 0,98 & 0,55 & 1,00 & 0,99 & 0,89 & 0,83 \\
\hline & $\mathrm{Al}_{\mathrm{KCl} 1} \mathrm{ES}$ & - & - & - & 0,41 & 0,98 & 0,99 & 0,95 & 0,65 \\
\hline & Soma ES ${ }^{(14)}$ & - & - & - & 0,33 & 0,99 & 0,99 & 0,87 & 0,71 \\
\hline & $\mathrm{Al}_{\mathrm{O}} \mathrm{ES}$ & 0,76 & - & - & - & 0,55 & 0,52 & 0,11 & 0,66 \\
\hline & Soma ES ${ }^{(15)}$ & - & - & - & 0,69 & 0,48 & 0,97 & 0,79 & 0,89 \\
\hline & $\mathrm{Al}_{\mathrm{KCl}, 0,1} \mathrm{ENS}$ & - & - & - & 0,76 & - & 0,99 & 0,89 & 0,69 \\
\hline & $\mathrm{Al}_{\mathrm{KCl1}} \mathrm{ENS}$ & - & - & - & - & - & - & 0,90 & 0,82 \\
\hline & $\mathrm{Al}_{\mathrm{O}} \mathrm{ENS}$ & - & - & - & - & 0,89 & 0,91 & - & 0,77 \\
\hline \multirow{9}{*}{$\mathrm{RS}$} & $\mathrm{Al}_{\mathrm{CaCl} 2} \mathrm{ES}$ & - & 0,99 & 0,99 & 0,59 & 0,99 & 0,99 & 0,97 & 0,77 \\
\hline & $\mathrm{Al}_{\mathrm{KCl} 0,1} \mathrm{ES}$ & - & - & 0,99 & 0,52 & 0,99 & 0,99 & 0,91 & 0,79 \\
\hline & $\mathrm{Al}_{\mathrm{KCl} 11} \mathrm{ES}$ & - & - & - & 0,59 & 0,99 & - & 0,95 & 0,80 \\
\hline & SomaES ${ }^{(14)}$ & - & - & - & 0,75 & 0,99 & 0,99 & 0,96 & 0,89 \\
\hline & $\mathrm{Al}_{\mathrm{OES}}$ & 0,59 & - & - & - & 0,61 & 0,59 & 0,80 & 0,60 \\
\hline & SomaES ${ }^{(15)}$ & - & - & - & 0,84 & 0,99 & 0,98 & 0,99 & 0,91 \\
\hline & $\mathrm{Al}_{\mathrm{KCl}, 1}$ ENS & - & - & - & - & - & 0,99 & 0,95 & 0,84 \\
\hline & $\mathrm{Al}_{\mathrm{KCl1}} \mathrm{ENS}$ & - & - & - & - & 0,99 & - & 0,95 & 0,80 \\
\hline & $\mathrm{Al}_{\mathrm{O}} \mathrm{ENS}$ & - & - & - & - & 0,97 & 0,97 & - & 0,88 \\
\hline \multirow{9}{*}{$\mathrm{BR}$} & $\mathrm{Al}_{\mathrm{CaCl} 2} \mathrm{ES}$ & - & 0,96 & 0,92 & 0,44 & 0,96 & 0,94 & 0,94 & 0,88 \\
\hline & $\mathrm{Al}_{\mathrm{KCl} 0,1} \mathrm{ES}$ & - & - & 0,98 & 0,64 & 0,99 & 0,99 & 0,99 & 0,65 \\
\hline & $\mathrm{Al}_{\mathrm{KCl} 1} \mathrm{ES}$ & - & - & - & 0,75 & 0,97 & 0,97 & 0,96 & 0,53 \\
\hline & SomaES ${ }^{(14)}$ & - & - & - & 0,63 & 0,99 & 0,99 & 0,98 & 0,82 \\
\hline & $\mathrm{Al}_{\mathrm{OES}}$ & 0,44 & - & - & - & 0,57 & 0,60 & 0,56 & 0,15 \\
\hline & Soma ES ${ }^{(15)}$ & - & - & - & 0,42 & 0,96 & 0,97 & 0,98 & 0,92 \\
\hline & $\mathrm{Al}_{\mathrm{KCl}, 1} \mathrm{ENS}$ & - & - & - & - & - & 0,99 & 0,99 & 0,76 \\
\hline & $\mathrm{Al}_{\mathrm{KCl} 11}$ ENS & - & - & - & - & - & - & 0,99 & 0,70 \\
\hline & $\mathrm{Al}_{\mathrm{O}} \mathrm{ENS}$ & - & - & - & - & 0,99 & 0,99 & - & 0,43 \\
\hline \multirow{9}{*}{ CB } & $\mathrm{Al}_{\mathrm{CaCl} 2} \mathrm{ES}$ & - & 0,99 & 0,99 & 0,80 & 0,99 & 0,96 & 0,99 & 0,93 \\
\hline & $\mathrm{Al}_{\mathrm{KCl} 0,1} \mathrm{ES}$ & - & - & 0,98 & 0,82 & 0,99 & 0,98 & 0,99 & 0,88 \\
\hline & $\mathrm{Al}_{\mathrm{KCl}} \mathrm{ES}$ & - & - & - & 0,78 & 0,97 & 0,99 & 0,97 & 0,76 \\
\hline & SomaES ${ }^{(13)}$ & - & - & - & 0,81 & 0,99 & 0,98 & 0,99 & 0,93 \\
\hline & $\mathrm{Al}_{\mathrm{OES}}$ & 0,65 & - & - & - & 0,83 & 0,85 & 0,79 & 0,49 \\
\hline & SomaES ${ }^{(14)}$ & & & & 0,95 & 0,95 & 0,96 & 0,93 & 0,88 \\
\hline & $\mathrm{Al}_{\mathrm{KCl}, 1}$ ENS & - & - & - & - & - & 0,98 & 0,99 & 0,97 \\
\hline & $\mathrm{Al}_{\mathrm{KCl} 11} \mathrm{ENS}$ & - & - & - & - & - & - & 0,97 & 0,79 \\
\hline & $\mathrm{Al}_{\mathrm{O}} \mathrm{ENS}$ & - & - & - & - & 0,99 & 0,97 & - & 0,81 \\
\hline
\end{tabular}

(1) AC9: coletado no Acre, Perfil 9; PE: coletado em Pernambuco; RS: coletado no Rio Grande do Sul: Rosário do Sul; BR: coletado em Bom Retiro-SC; CB; coletado em Curitibanos, SC;(2) Alumínio extraído pelos diferentes extratores e métodos de extração; ${ }^{(3)}$ Espectrofotometria de absorção atômica; ${ }^{(4)} \mathrm{e}^{(5)}$ Extração química sequencial e não sequencial, respectivamente; (6) Alumínio extraído com a solução de cloreto de cálcio $0,01 \mathrm{~mol} \mathrm{~L}^{-1} ;{ }^{(7)} \mathrm{e}^{(10)}$ Alumínio extraído com a solução de $\mathrm{KCl} 0,1 \mathrm{~mol} \mathrm{~L}^{-}$ ${ }^{1}$, (8) $\mathrm{e}^{(11)}$ Alumínio extraído com a solução de $\mathrm{KCl}_{1} \mathrm{~mol} \mathrm{~L}^{-1} ;{ }^{(9)} \mathrm{e}^{(12)}$ Alumínio extraído com a solução de oxalato de amônio

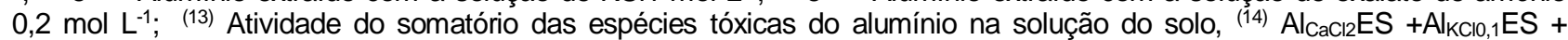
$+\mathrm{Al}_{\mathrm{KCl} 1} \mathrm{ES} \mathrm{e}^{\left({ }^{(15)} \mathrm{Al}\right.} \mathrm{AaCl}_{2} \mathrm{ES}+\mathrm{Al}_{\mathrm{KCl}, 1} \mathrm{ES}+\mathrm{Al}_{\mathrm{KCl} 1} \mathrm{ES}+\mathrm{Al} \mathrm{OES}$. ${ }^{(1)} \mathrm{AC9}$ : collected in Acre, Profile 9; PE: collected in Pernambuco; RS: collected in Rio Grande do Sul; BR: collected in Bom Retiro, SC; CB; collected in Curitibanos, SC; (2) Aluminum extracted by the different extractors and extraction methods; (3) Atomic absorption spectrophotometry, ${ }^{(4)}$ and (5) sequential and nonsequential chemical extraction, respectively; (6) Aluminum extracted with $0.01 \mathrm{~mol} \mathrm{~L}^{-1}$ calcium chloride solution; (7) and (10) Aluminum extracted with $\mathrm{KCl}$ solution $0.1 \mathrm{~mol} \mathrm{~L}^{-1},{ }^{\left({ }^{(8)}\right.}$ and ${ }^{(11)}$ Aluminum extracted with the $\mathrm{KCl} 1 \mathrm{~mol} \mathrm{~L}^{-1}$ solution; (9) and (12) Aluminum extracted with $0.2 \mathrm{~mol} \mathrm{~L}^{-1}$ ammonium oxalate solution; ${ }^{(13)}$ Activity of the sum of the toxic species of aluminum in the soil solution, ${ }^{(14)} \mathrm{AlCaCl}_{2} \mathrm{ES}+\mathrm{AlKCl} 0,1 \mathrm{ES}+\mathrm{AlKCl} 1 \mathrm{ES}$ and ${ }^{(15)} \mathrm{AlCaCl}_{2} \mathrm{ES}+\mathrm{AlKCl}, 1 \mathrm{ES}+\mathrm{AlKCl} 1 \mathrm{ES}+\mathrm{AIOES}$. 


\section{Considerações sobre os extratores utilizados para a extração de Al}

Levando-se em consideração os teores muito elevados e elevados de $\mathrm{Al}-\mathrm{KCl}$, quantificados por titulação e por EAA (dados não apresentados), nos solos AC9, PE, RS e BR (acima de 10 e $4 \mathrm{cmol}_{c} \mathrm{~kg}^{-1}$, respectivamente) (Figuras 2a a 2d) e o efeito da alta concentração salina que induz a dissolução de frações não trocáveis de Al, superestimando o Al "trocável", Cunha et al. (2015), utilizando esses mesmos solos, sugeriram a utilização da solução mais diluída de $\mathrm{KCl}$ $0,1 \mathrm{~mol} \mathrm{~L}^{-1} \mathrm{com}$ o objetivo de minimizar o efeito do sal e da concentração salina da solução na solubilização de frações de Al eventualmente não trocáveis. Nesses estudos, os autores encontraram que os teores de Al extraídos e o pH do extrato dessa solução foram inferiores aos da solução de $\mathrm{KCl} 1 \mathrm{~mol} \mathrm{~L}^{-1} \mathrm{e}$ sugeriram que os menores teores desse elemento, quantificados na solução 10 vezes mais diluída, estão relacionados com a menor hidrólise dos compostos inorgânicos amorfos e/ou de compostos orgânicos de $\mathrm{Al}$, representando, assim, mais realisticamente o Al adsorvido por reações de troca iônica pelo $\mathrm{K}$, sendo este considerado pelos autores como promissor para a determinação de Al trocável nesses solos.

Tabela 3 - Correlações entre os teores de cálcio e magnésio extraídos com as soluções de $\mathrm{KCl} 0,1$ e $1 \mathrm{~mol} \mathrm{~L}^{-1}$ e com a água ultrapura (AU) em amostras de cinco perfis de solos ácidos brasileiros, incubados por 98 dias e cultivados com soja durante 60 dias, ambos em casa de vegetação. Correlations between the calcium and magnesium contents extracted with 0.1 and $1 \mathrm{~mol} \mathrm{~L}^{-1} \mathrm{KCl}$ solutions and ultrapure water (AU) in samples of five Brazilian acid soils profiles incubated for 98 days and cultivated with soybeans for 60 days, both under greenhouse conditions.

\begin{tabular}{|c|c|c|c|c|c|c|c|c|}
\hline \multirow{3}{*}{ (1) Solo } & \multicolumn{8}{|c|}{ Elemento Extrator } \\
\hline & & (2) Саксl 1 & (3) $\mathrm{CaKCl} \mathrm{0,1}$ & (4) $\mathrm{CaAU}$ & & (5) $\mathrm{MgKCl} 1$ & (6) $\mathrm{MgKCl}_{0,1}$ & (7) $\mathrm{Mg}_{\mathrm{AU}}$ \\
\hline & & \multicolumn{3}{|c|}{$r$} & & \multicolumn{3}{|c|}{$r$} \\
\hline \multirow{2}{*}{ AC9 } & Саксl1 & - & 0,42 & 0,89 & $\mathrm{Mg}_{\mathrm{KCl1}}$ & - & 0,90 & 0,52 \\
\hline & Саксі0,1 & - & - & 0,89 & $\mathrm{Mg}_{\mathrm{KCl}, 0,1}$ & - & - & 0,57 \\
\hline \multirow[t]{2}{*}{$\mathrm{PE}$} & Саксl1 & - & 0,99 & 0,98 & MgkCl1 & - & 0,94 & 0,88 \\
\hline & СаксI0,1 & - & - & 0,98 & $\mathrm{Mg}_{\mathrm{KCl}}, 1$ & - & - & 0,90 \\
\hline \multirow[t]{2}{*}{ RS } & Саксl1 & - & 0,95 & 0,98 & $\mathrm{Mg}_{\mathrm{KCl1}}$ & - & 0,69 & 0,76 \\
\hline & СаксI0,1 & - & - & 0,91 & $\mathrm{Mg}_{\mathrm{KCl}, 1}$ & - & - & 0,95 \\
\hline \multirow[t]{2}{*}{ BR } & Саксl1 & - & 0,99 & 0,94 & $\mathrm{Mg}_{\mathrm{KCl1}}$ & - & 0,99 & 0,95 \\
\hline & Саксі0,1 & - & - & 0,93 & $\mathrm{Mg}_{\mathrm{KCl}, 1}$ & - & - & 0,97 \\
\hline \multirow[t]{2}{*}{ CB } & Саксl1 & - & 0,99 & 0,99 & MgkCl1 & - & 0,99 & 0,96 \\
\hline & Саксі0,1 & - & 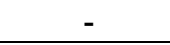 & 0,98 & Mgkcio,1 & - & - & 0,97 \\
\hline
\end{tabular}

(1) Acre: Perfil 9 (AC9), PE: Pernambuco, Rio Grande do Sul: Rosário do Sul (RS), Santa Catarina: Bom Retiro (BR) e Curitibanos (CB). (2), ${ }^{(3)} \mathrm{e}^{(4)}$, representam, respectivamente, o cálcio extraído pelas soluções de $\mathrm{KCl} 1$ e $0,1 \mathrm{~mol} \mathrm{~L}^{-1}$ e pela água ultrapura e; ${ }^{(5)},{ }^{(6)}$ e ${ }^{(7)}$ o magnésio extraído por essas mesmas soluções. (1) AC9: collected in Acre, Profile 9; PE: collected in Pernambuco; RS: collected in Rio Grande do Sul; BR: collected in Bom Retiro, SC; CB; collected in Curitibanos, $S C$; (2), (3) and ${ }^{(4)}$, represent, respectively, the calcium extracted by the solutions of $\mathrm{KCl} 1$ and $0.1 \mathrm{~mol}^{\mathrm{L}^{-1}}$ and by ultrapure water and; (5), (6) and (7) the magnesium extracted by these same solutions

Entretanto, contrariando essa expectativa, isto não se concretizou neste estudo, pois a utilização desse sal $(\mathrm{KCl})$, independentemente da concentração salina utilizada, extraiu quantidades altamente correlacionáveis entre si, de $\mathrm{Ca}^{2+}, \mathrm{Mg}^{2+}$ e $\mathrm{Al}^{3+}$, não havendo, portanto, razão plausível para a mudança de método. Ambos os métodos tiveram alta correlação com o $\mathrm{Ca}^{2+} \mathrm{e} \mathrm{Mg}^{2+}$ na maioria das amostras de solo extraídas com água ultrapura (utilizada para a extração da solução do solo) (Tabela 3) que representa a disponibilidade desses nutrientes para as plantas.

A solução de $\mathrm{CaCl}_{2} \quad 0,01 \mathrm{~mol}^{-1}$, naquele mesmo estudo (Cunha et al., 2015), também foi considerada como promissora para a indicação do Al em equilíbrio mais imediato com o $\mathrm{Al}$ da solução, assim como de seu potencial de toxicidade. Entretanto, esse método necessita ser calibrado para diferentes classes de solos, definindo intervalos de teores de Al nos solos, que podem ser considerados críticos para as culturas, com base em experimentos de campo e casa de vegetação, com cultivos de plantas, antes de ser recomendado como método de rotina (Cunha et al., 2015). Além disso, houve alta correlação entre o AlcaCl2 com o Alkcl1ES, com o Alkc11ENS e com a A\&FTAl na solução do solo (Tabela 2).

\section{Alumínio extraído com diferentes extratores e sua toxicidade às plantas de soja}

A calagem promoveu aumento significativo do $\mathrm{pH}$, das bases trocáveis, da soma e da saturação por bases, tanto nos solos como na solução destes (Tabela4), principalmente naqueles em que seus teores eram baixos ou muito baixos (PE, BR e CB), resultando numa considerável diminuição nos teores de Al-KCl. No entanto, nos solos AC9 e PE, mesmo com a utilização da dose mais alta (equivalente à dose necessária para neutralização de $100 \%$ do teor de $\mathrm{H}+\mathrm{Al}$ ), os teores de $\mathrm{Al}-\mathrm{KCl}$ mantiveram-se altos, com valores de 3,59 e $1,85 \mathrm{cmol}_{\mathrm{c}} \mathrm{kg}^{-1}$, respectivamente 
(Figuras $2 \mathrm{a}$ e $2 \mathrm{~b}$, respectivamente). A não neutralização completa do $\mathrm{Al}$ pode ter ocorrido devido à subestimação do $\mathrm{H}+\mathrm{Al}$ pelo acetato de cálcio (Júnior et al., 2015), uma vez que podem existir outras frações de $\mathrm{Al}$ que não foram computadas pelo acetato de cálcio, que interferem na quantificação da acidez potencial dos solos, subestimando, assim, a necessidade de calcário. Além disso, os ânions resultantes de sua dissolução, responsáveis pela correção da acidez, são também consumidos nas reações com outros cátions ácidos $\left(\mathrm{Al}^{3+}, \mathrm{Mn}^{2+}\right.$ e $\left.\mathrm{Fe}^{2+}\right)$ na camada de deposição do calcário (Ernani et al., 2007; Caires et al., 2008).

A produção de matéria seca total (MST) (Figura 3a) e o crescimento do sistema radicular (CSR) apresentaram ajuste quadrático e alta correlação, em função das doses de calcário, em todos os solos (Figuras 3a e 3b, respectivamente).
No solo AC9, foram obtidos teores muito elevados de $\mathrm{Al}-\mathrm{KCl}$ e do Alo pelos métodos da ES e ENS, em relação aos outros extratores (Figura $2 a$ ), elevada atividade e somatório das espécies tóxicas de Al na solução do solo (AETAl e A\&FTAl, respectivamente) (Tabela 3 ). Mesmo assim, observase que não houve resposta desse solo à calagem, uma vez que a maior produção de MST (Figura 3a) ocorreu nos tratamentos sem calcário. Isso ocorreu mesmo com o aumento do CSR (Figura 3b), o Al estando acima de $13 \mathrm{cmol}_{\mathrm{c}} \mathrm{kg}^{-1}$ (Figura 2a), representando em termos de A\&FTAl 10,63 $\mu \mathrm{mol} \mathrm{L}^{-1}$, considerada muito elevada, uma vez que está acima do nível crítico preconizado na literatura, de 4,6 $\mathrm{mmol} \mathrm{L}^{-1}$ (Silva et al., 2001), pH 4,85 e saturação de Al de $40 \%$ (Tabela 4).

Tabela4 - Atividade das espécies tóxicas de alumínio na solução de amostras de solo e alguns atributos químicos da solução do solo, e do solo de cinco perfis de solos ácidos brasileiros. Activity of the toxic species of aluminum in the soil solution and some chemical attributes of the soil and soil solution of five profiles of Brazilian acid soils.

\begin{tabular}{|c|c|c|c|c|c|c|c|c|c|c|c|c|c|}
\hline \multirow{3}{*}{ (1) Solo } & \multirow{3}{*}{ (2) Hor. } & \multirow{2}{*}{ (3) D. Cal. } & \multicolumn{6}{|c|}{ 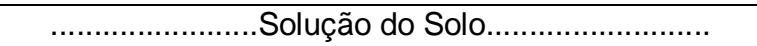 } & \multicolumn{5}{|c|}{.Trocável.. } \\
\hline & & & $\mathrm{Al}^{3+}$ & $\mathrm{AlOH}^{2+}$ & $\mathrm{Al}(\mathrm{OH})_{2}^{+}$ & (4) $A \sum F T A I$ & (5) $\mathrm{S}$ & (6) $\mathrm{m}$ & $\mathrm{Al}^{3+}$ & (7) $\underline{S}$ & (8) & (9) $\mathrm{m}$ & \multirow[t]{2}{*}{$P$} \\
\hline & & $\mathrm{H}+\mathrm{Al}\left(\mathrm{t} \mathrm{ha}^{-1}\right)$ & & $\ldots \ldots(\mu \mathrm{n}$ & $\left.101 \mathrm{~L}^{-1}\right) \ldots$ & ............. & $\left(\mathrm{mmol} \mathrm{L}^{-1}\right)$ & $(\%)$ & $(\mathrm{cmo}$ & $\left.\mathrm{I}_{\mathrm{C}} \mathrm{kg}^{-1}\right)$ & & \%) & \\
\hline \multirow{4}{*}{ AC9 } & \multirow{4}{*}{$\mathrm{Bt}_{2}$} & 0 & 7,93 & 2,3 & 0,4 & 10,63 & 1,4 & 1,0 & 13,8 & 20,9 & 57 & 40 & 17,2 \\
\hline & & 0,25 & 2,31 & 3,4 & 3,2 & 8,91 & 1,3 & 0,8 & 9,6 & 23,1 & 66 & 29 & 15,8 \\
\hline & & 0,5 & 0,91 & 2,0 & 2,7 & 5,61 & 0,9 & 0,4 & 5,9 & 25,2 & 75 & 19 & 15,8 \\
\hline & & 1 & 0,24 & 1,0 & 2,6 & 3,84 & 0,8 & 0,2 & 3,6 & 31,4 & 83 & 10 & 17,2 \\
\hline \multirow{4}{*}{ PE } & \multirow{4}{*}{$\mathrm{Bt}_{2}$} & 0 & 33,4 & 7,7 & 1,0 & 42,1 & 0,8 & 6,6 & 19,8 & 4,4 & 18 & 82 & 27,2 \\
\hline & & 0,25 & 6,0 & 2,9 & 0,9 & 9,8 & 0,8 & 1,7 & 14,6 & 9,1 & 36 & 62 & 23,5 \\
\hline & & 0,5 & 0,8 & 1,0 & 0,9 & 2,7 & 0,9 & 0,8 & 9,8 & 12,5 & 52 & 44 & 21,7 \\
\hline & & 1 & 0,0 & 0,1 & 0,2 & 0,3 & 1,1 & 0,2 & 1,8 & 19,8 & 82 & 8 & 16,5 \\
\hline \multirow{4}{*}{ RS } & \multirow{4}{*}{$\mathrm{Bt}_{3}$} & 0 & 2,48 & 2,1 & 1,0 & 5,66 & 0,8 & 0,9 & 6,7 & 11,5 & 55 & 37 & 16,4 \\
\hline & & 0,25 & 0,44 & 0,7 & 0,7 & 1,84 & 0,7 & 0,4 & 4,6 & 12,3 & 62 & 27 & 16,5 \\
\hline & & 0,5 & 0,10 & 0,4 & 1,0 & 1,5 & 0,8 & 0,4 & 2,6 & 13,2 & 70 & 16 & 15,5 \\
\hline & & 1 & 0,00 & 0,0 & 0,1 & 0,1 & 1,4 & 0,1 & 0,2 & 19,8 & 87 & 1 & 12,1 \\
\hline \multirow{4}{*}{ BR } & \multirow{4}{*}{$B_{i}$} & 0 & 20,21 & 10,3 & 3,0 & 33,51 & 0,3 & 13,9 & 6,7 & 0,4 & 4 & 95 & 9,4 \\
\hline & & 0,25 & 3,57 & 5,1 & 4,8 & 13,47 & 0,6 & 1,4 & 4,4 & 3,4 & 30 & 56 & 10,8 \\
\hline & & 0,5 & 0,25 & 1,0 & 2,3 & 3,55 & 0,6 & 0,5 & 2,2 & 5,7 & 50 & 28 & 7,6 \\
\hline & & 1 & 0,03 & 0,3 & 1,3 & 1,63 & 1,0 & 0,1 & 0,3 & 9,4 & 72 & 3 & 9,4 \\
\hline \multirow{4}{*}{ CB } & \multirow{4}{*}{$\mathrm{Bw}_{3}$} & 0 & 6,50 & 2,9 & 0,7 & 10,1 & 0,3 & 4,0 & 2,2 & 0,4 & 5 & 86 & 3,6 \\
\hline & & 0,25 & 1,95 & 3,6 & 4,4 & 9,95 & 0,6 & 0,8 & 1,2 & 2,3 & 24 & 33 & 3,4 \\
\hline & & 0,5 & 0,16 & 0,7 & 1,8 & 2,66 & 0,7 & 0,3 & 0,3 & 4,4 & 45 & 7 & 2,4 \\
\hline & & 1 & 0,02 & 0,2 & 0,8 & 1,02 & 1,2 & 0,1 & 0,02 & 6,8 & 66 & 0 & 3,3 \\
\hline
\end{tabular}

(1) Acre: Perfil 9 (AC9), PE: Pernambuco, Rio Grande do Sul: Rosário do Sul (RS), Santa Catarina: Bom Retiro (BR) e Curitibanos (CB); (2) Horizontes coletados; ${ }^{(3)}$ Doses de calcário aplicadas; (4) Atividade do somatório das formas tóxicas do alumínio na solução do solo; (5) e ${ }^{(7)}$ Soma de bases da solução do solo e do solo, respectivamente;(6) Fração do alumínio em relação a todos os cátions; ${ }^{(8)}$ Saturação por bases; ${ }^{(9)}$ Saturação por alumínio. ${ }^{(1)}$ AC9: collected in Acre, Profile 9; PE: collected in Pernambuco; RS: collected in Rio Grande do Sul; BR: collected in Bom Retiro, SC; CB; collected in Curitibanos, SC; (3) Doses of limestone applied; (4) Activity of the sum of the toxic forms of aluminum in the soil solution; (5) and (7) Sum of bases of soil and soil solution, respectively; ${ }^{(6)}$ Fraction of aluminum in relation to all cations; ${ }^{(8)}$ Base saturation; ${ }^{(9)}$ Aluminum saturation.

O solo RS tem o mesmo comportamento em relação aos teores de Al (Figura 2c) do solo AC9, exceto para a AETAl e para A\&FTAI (Tabela 4), que foram as menores entre todos os solos, notadamente nos tratamentos sem calcário. Com a utilização da primeira dose de calcário ( $25 \%$ do teor de $\mathrm{H}+\mathrm{Al})$, houve aumento da soma e saturação por base, que já eram elevadas (Tabela 4), diminuição dos teores de Al extraídos pelos extratores (Figura 2c) e redução da $\mathrm{m} \%$ de 37 para $27 \%$ (ideal para um bom desenvolvimento dessa cultura, segundo Smyth \& Cravo, 1992). Entretanto, a maior produção de MST (Figura 3a) foi observada com a utilização da primeira dose de calcário, sendo similar à da segunda $(50 \%$ do teor de $\mathrm{H}+\mathrm{Al}$ ), decrescendo com a dose máxima ( $100 \%$ do teor de $\mathrm{H}+\mathrm{Al}$ ), mesmo havendo decréscimo 
no CSR (Figura 3b). Isso leva a crer que, para os solos AC9 e RS, apesar da alta correlação entre o Al$\mathrm{KCl}$ e a A乏FTAl (Tabela 2), isto pode não estar indicando somente as formas tóxicas de Al presente na solução do solo dos mesmos.

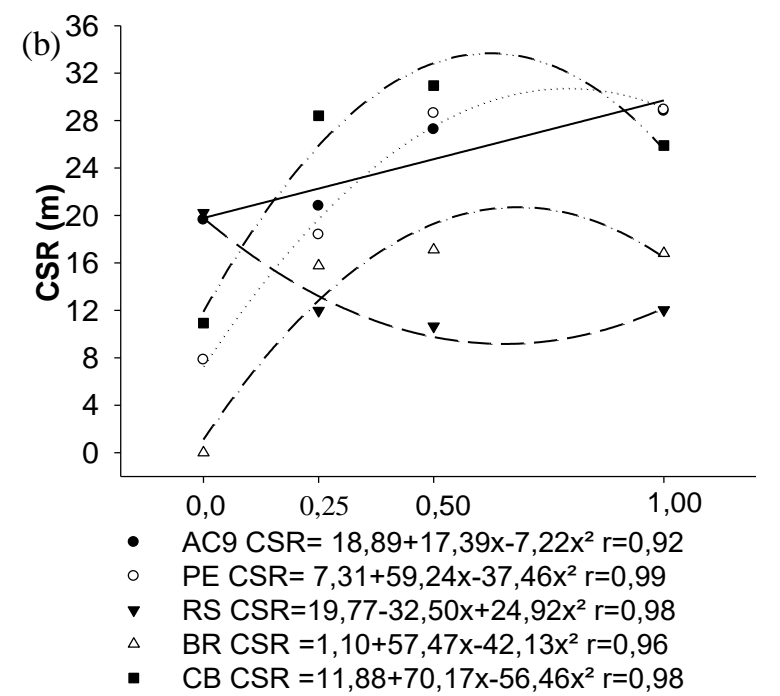

Doses de calcário $\times \mathrm{H}+\mathrm{Al}\left(\mathrm{t} \mathrm{ha}{ }^{-1}\right)$

Figura 3 - Relação entre as doses de calcárioe: a) matéria seca total (MST) e b) o crescimento do sistema radicular (CSR) das plantas de soja cultivadas em casa de vegetação, durante 60 dias nos solos do:Acre (AC9); Pernambuco (PE); Rosário do Sul (RS); Bom Retiro (BR); e Curitibanos (CB). Relationship between limestone doses and: a) total dry matter (MST) and b) root system growth (RSG) of soybean plants grown in greenhouse for 60 days in the soils of: Acre (AC9); Pernambuco (PE); Rosário do Sul (RS); Bom Retiro (BR), and Curitibanos (CB).

A pouca ou nenhuma manifestação de toxicidade do Al nas plantas de soja, cultivadas nos solos AC9 e RS, está relacionada com a relação do $\mathrm{Ca}^{2+}$ e do $\mathrm{Mg}^{2+}$ com o $\mathrm{Al}$ trocável e com o $\mathrm{Al}$ da solução do solo. Para esses solos (AC9 e RS), notadamente nos tratamentos sem calcário, mesmo com a m\% estando na faixa de 30 a $40 \%$, que poderiam ser considerados valores elevados para a maioria das culturas (Cunha, 2017; Hashimoto et al., 2010), as relações $(\mathrm{Ca}+\mathrm{Mg}) / \mathrm{Al}$ e Ca/Al trocáveis para o solo AC9 foram de 1,66 e 1,28, respectivamente, e para o solo RS de 1,66 e 1,28, respectivamente. Já essas mesmas relações na solução do solo foram de 9,07 e 6,69, respectivamente, para o AC9 e de 9,25 e 5,75 , respectivamente, para o RS. Os valores dessas relações, portanto, são bem mais altos do que os preconizados como adequados na literatura, principalmente para a relação $\mathrm{Ca} / \mathrm{Al}$ trocável, indicada como 0,42 por Smyth \& Cravo (1992) e como 0,48 por Gama \& Kiehl (1999). Isso indica que solos que possuem quantidades de cálcio superiores às do $\mathrm{Al}$, suficientes para manter a relação $\mathrm{Ca} / \mathrm{Al}$ trocável elevada, as plantas podem não ser afetadas por elevadas quantidades de Al (Gama \& Kiehl, 1999) na solução do solo.

Nos solos PE e BR, diferentemente dos demais (AC9, RS e CB), nos tratamentos sem calcário, foram encontrados elevados teores de Al extraídos pelos diferentes extratores, métodos de extração e quantificação (Figuras $2 \mathrm{~b}$ e $2 \mathrm{~d}$, respectivamente), elevadas AETAI $(33,4$ e $\left.20,21 \mu \mathrm{mol} \mathrm{L}^{-1}\right)$ e A\&FTAl $\left(42,1\right.$ e $\left.33,51 \mu \mathrm{mol} \mathrm{L}^{-1}\right)$, ambas muito acima do valor crítico de $4,6 \mu \mathrm{mol} \mathrm{L}^{-1}$, indicando potencial de elevada toxicidade de Al às plantas. O mesmo ocorreu para a $\mathrm{m} \%$ e para a fração do Al em relação a todos os cátions da solução do solo (Tabela4). Diante disso, o Al parece ter sido o responsável direto pela baixa produção de MST e pelo baixo CSR das plantas cultivadas nesses solos, nos tratamentos sem calcário (Figuras $3 a$ e $3 b$, respectivamente). Entretanto, observa-se que a produção de MST e CSR foram maiores na segunda dose de calcário, porém muito similares às da primeira. Com a utilização da dose máxima, ambos os solos continuaram respondendo à calagem, notadamente no solo BR (Figura 3a), mesmo com a $\mathrm{m} \%$ do solo em níveis considerados elevados para essa cultura (Tabela4).

Por outro lado, no solo $\mathrm{CB}$, observa-se que a AETAl, a A\&FTAl, a m\%e da fração do $\mathrm{Al}$, em relação a todos os cátions na solução, foram elevadas (Tabela 4), e os teores de Al extraídos pelos diferentes extratores, métodos de extração e quantificação foram similares (Figura 2e), exceto para o AloES, em que os teores desse elemento se encontraram em níveis mais elevados (Figura $2 \mathrm{e}$ ) e o AloENS mais inferiores em relação aos outros solos (Figuras 2a a 2d). O Al nesse solo, nos tratamentos sem calcário, limitou menos a produção de MST (Figura 3a) e do CSR (Figura 3b) do que nos solos PE e BR. Porém, com a aplicação da 
primeira dose de calcário, a $\mathrm{m} \%$ do solo diminuiu de $86 \%$ para $33 \%$, proporcionando boa produção de MST e do CSR, aumentando ainda mais com a aplicação da segunda dose do corretivo, em que a $\mathrm{m} \%$ era de $7 \%$, notadamente no CSR (Figura 3b).Diante disso, o Al-KCl parece estar indicando, de forma adequada, uma eventual condição de toxicidade desse elemento às plantas cultivadas nesses solos (PE, BR e $C B$ ).

A toxicidade do Al nos solos PE, BR e CB, sobretudo nos tratamentos sem calcário, é explicada pelas baixas relações $(\mathrm{Ca}+\mathrm{Mg}) / \mathrm{Al}$ e $\mathrm{Ca} / \mathrm{Al}$ trocáveis no solo. No $\mathrm{PE}$, essas relações foram, respectivamente, de 0,20 e 0,09; para os solos BR e CB, essas relações foram semelhantes, de 0,02 e 0,08, respectivamente. $\mathrm{Na}$ solução desses mesmos solos, as relações $(\mathrm{Ca}+\mathrm{Mg}) / \mathrm{Ale} \mathrm{Ca} / \mathrm{Al}$ foram, respectivamente, de 1,15 e 0,32 no PE; 0,32 e 0,21 no BR; e 1,0 e 0,75 no CB. Esses valores são muito mais baixos do que os obtidos nos solos AC9 e RS, demonstrando que o Al presente nesses solos (PE, BR e CB) está exercendo efeitos tóxicos às plantas, uma vez que as quantidades de $\mathrm{Ca}$ e $\mathrm{Mg}$, tanto trocáveis quanto na solução do solo, eram mais baixas do que o Al.

Com a aplicação da primeira dose de calcário (25\% do teor de $\mathrm{H}+\mathrm{Al}$ ), mesmo com a $\mathrm{m} \%$ do solo elevada $(\mathrm{PE}=62 \%, \mathrm{SCBR}=56 \%$ e $\mathrm{CB}=33 \%)$, as relações $(\mathrm{Ca}+\mathrm{Mg}) / \mathrm{Al}$ e $\mathrm{Ca} / \mathrm{Al}$ trocáveis situaram-se acima do limite crítico (PE: $(\mathrm{Ca}+\mathrm{Mg}) / \mathrm{Al}=0,60$, $\mathrm{Ca} / \mathrm{Al}=0,34$; $\mathrm{BR}:(\mathrm{Ca}+\mathrm{Mg}) / \mathrm{Al}=0,73, \mathrm{Ca} / \mathrm{Al}=0,48$ e $\mathrm{CB}$ : $(\mathrm{Ca}+\mathrm{Mg}) / \mathrm{Al}=1,84, \mathrm{Ca} / \mathrm{Al}=1,20)$, referidos na literatura para a relação $\mathrm{Ca} / \mathrm{Al}(0,42$ e 0,48$)$. Nestes casos, os teores expressivamente elevados (PE) e elevados (BR) de Al-KCl, indicados nas análises, podem não estar prejudicando o desenvolvimento das plantas, porém as mesmas continuaram respondendo à calagem nas doses mais altas. Já na solução do solo com o emprego dessa mesma dose, os valores das relações $(\mathrm{Ca}+\mathrm{Mg}) / \mathrm{Al}$ e $\mathrm{Ca} / \mathrm{Al}$ foram, respectivamente, de 5,2 e 0,21 no PE; 6,2 e 3,2 no SCBR; e de 10,2 e 4,8 no SCCB, superiores, portanto, às relações obtidas para esses elementos na forma trocável. Isto leva a crer que, a partir dessa dose de calcário, o Al pode não estar exercendo toxicidade às plantas ou esse efeito é pequeno.Portanto, mesmo que os teores de Al-KCl estejam evidenciando essa condição, parece plausível considerar a hipótese de que, para esses solos, o emprego de $1 / 4$ ou $1 / 2$ da dose de calcário $(\mathrm{pH}$ em água variando de 4,9 a 5,2 ) seja suficiente para permitir que haja um equilíbrio adequado entre os cátions básicos e ácidos na solução, suficientes para garantir que as plantas expressem bom potencial produtivo.

Cabe salientar que a falta de resposta das plantas nos solos AC9 e RS pode estar relacionada, também, com a interação entre os íons na solução do solo que, na maioria das vezes, podem existir numa concentração efetiva menor do que a concentração analítica, o que determina menor potencial químico do elemento, refletindo na menor toxicidade de $\mathrm{Al}$ às plantas (Matúš, 2007; Nolla et al., 2015). Portanto, a utilização da atividade desse elemento, no lugar da concentração, tem melhor relação com a resposta das plantas (Spera et al., 2014). Além disso, deve estar relacionada com os teores de $P$ aplicados (Tabela 4). Quando o efeito do Al for no crescimento de raízes, aumentando os teores de $P$, não há resposta das plantas à calagem, uma vez que maiores teores de $\mathrm{P}$ no solo diminuem a dependência de um amplo sistema radicular para absorver esse nutriente, como também verificado por Ernani et al. (2004), Rutkowska et al. (2015) e Nolla et al. (2013a e 2013b). É importante também frisar que, embora a fertilização dos solos com N, P e K tenha sido realizada conforme a CQFS-RS/SC (2004), que preconiza a recomendação desses macronutrientes para experimentos tanto a campo como em lavouras convencionais, verificou-se que, mesmo em condição de experimentos em casa de vegetação, em que há o confinamento e o desenvolvimento limitado de raízes,as plantas não manifestaram nenhum tipo de deficiência nutricional (dados não mostrados) que pudessem explicar a resposta ou não das mesmas à calagem e, consequentemente, a redução ou não do seu potencial produtivo. Esses resultados podem ser verificados em Cunha (2017).

\section{Extrator que melhor identificou o potencial tóxico do $\mathrm{Al}$ às plantas}

Comparando os tratamentos após extração com cloreto de cálcio $0,01 \mathrm{~mol} \mathrm{~L}^{-1}$ e quantificação por titulação (Figuras $2 \mathrm{a}$ a $2 \mathrm{e}$ ), constatou-se mais $\mathrm{Al}$ extraído por este extrator nos solos $\mathrm{PE}, \mathrm{BR}$ e $\mathrm{CB}$, os quais responderam mais à calagem com os teores de AlkcIENS (valores considerados como referência nessa interpretação), que foram de 2,63; 1,82 e $0,89 \mathrm{cmolc}_{\mathrm{c}} \mathrm{kg}^{-1}$, nos tratamentos sem calcário (Figuras 2b, $2 \mathrm{~d}$ e $2 \mathrm{e}$, respectivamente). Neste sentido, nos solos AC9 e RS, em que as plantas mostraram nenhuma ou pouca resposta à calagem, respectivamente, os teores de AlkC11ENS e AlkCl1ES mantiveram-se em níveis bastante elevados (Figuras 2a e 2c, respectivamente), os quais poderiam ser indicativos de elevada toxicidade pelo $\mathrm{Al}$, porém os teores de $\mathrm{Al}_{\mathrm{CaCl}} \mathrm{ES}$ foram bem mais baixos na ausência de calagem $\left(0,57\right.$ e 0,67 cmolc $\mathrm{kg}^{-1}$, respectivamente). Isso sugere que o Al extraído com a solução de $\mathrm{KCl} 1 \mathrm{~mol} \mathrm{~L}^{-1}$ nos solos AC9 e RS não é o trocável, podendo estar sendo artificialmente solubilizado pela solução de $\mathrm{KCl} 1 \mathrm{~mol} \mathrm{~L}^{-1}$.

Embora tenha havido alta correlação entre os métodos de extração e entre esses métodos com a solução do solo (Tabela 4), o $\mathrm{CaCl}_{2}$ foi o extrator que melhor discriminou os solos quanto a resposta à calagem, além de estimar bem os solos em que as plantas poderiam estar manifestando os sintomas de toxicidade por Al, principalmente nos solos AC9 e PE. Portanto, os melhores parâmetros a serem avaliados para se explicar as respostas das plantas são a atividade do $\mathrm{Al}^{3+}$ na solução do solo, a $\mathrm{m} \%$ do solo e o

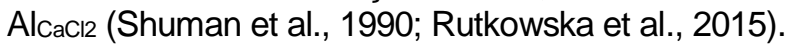




\section{Conclusões}

O aumento do $\mathrm{Al}-\mathrm{KCl}$ nos solos estudados, verificados pelos métodos das extrações químicas sequenciais e não sequenciais, está relacionado com a dissolução de outras frações de Al (amorfas, fracamente retidas nos coloides dos solos e complexadas na matéria orgânica), além da trocável.

Nos solos AC9 e RS, as frações de Al não estão relacionadas com a toxicidade desse elemento às plantas de soja. Nos solos PE, BR e CB, as frações de Al verificadas nesses solos estão relacionadas com a toxicidade desse elemento às plantas avaliadas.

A solução de $\mathrm{KCl}$ e mol $\mathrm{L}^{-1}$ não foi eficaz em extrair somente as frações de Al trocáveis nos solos com alta fertilidade natural (AC9 e RS). Nos solos mais intemperizados e ácidos (PE, BR e CB), essa solução foi eficaz na determinação das frações trocáveis e do potencial tóxico desse elemento às plantas.

O cloreto de cálcio foi o extrator que melhor discriminou os solos quanto ao potencial tóxico do $\mathrm{Al}$ às plantas estudadas.

\section{Agradecimentos}

À CAPES-FAPESC, pela concessão da bolsa ao primeiro autor; às unidades da Embrapa Rio Branco e Recife, pela disponibilidade, pela coleta e posterior envio das amostras de solo dos Estados do Acre e Pernambuco, imprescindíveis para a realização deste estudo.

\section{Referências}

Almeida JA, Ernani PR (1996) Influência do solvente, da relação solo/solvente, e da incubação das amostras úmidas na variação do $\mathrm{pH}$ dos solos catarinenses. Ciência Rural 26(1):81-85.

Araújo EA, Lani JL, Amaral EF, Guerra A (2004) Uso da terra e propriedades físicas e químicas de Argissolo Amarelo distrófico na Amazônia Ocidental. Revista Brasileira de Ciência do Solo 28(2):307-315.

Auxtero E, Madeira M, Parker D (2012) Extractable Al and soil solution ionic concentration in strongly leached soils from Northwest lberia: Effects of liming. International Scholarly Research Notices Soil Science 2012:1-15.

Bernini TA, Pereira MG, Fontana A, Anjos LHC, Calderano SB, Wadt PGS, Moraes AGL, Santos LL (2013) Taxonomia de solos desenvolvidos sobre depósitos sedimentares da Formação Solimões no Estado do Acre. Bragantia72 (1):71-80.

Boeira RC, Raij B van, Silva AS, Maximiliano VCB (2004) Extração simultânea de alumínio, cálcio, magnésio, potássio e sódio do solo com solução de cloreto de amônio. Revista Brasileira de Ciência do Solo 28 (5):929-936.
Caballero EC, Álvarez VVH, César JLN (2015) Comparação de diferentes métodos químicos como extrantes de alumínio em solos tiomórficos do Brasil e Colômbia. Revista Facultad Nacional de Agronomía Medelín, 68(1):7569-7579.

Caires EF, Garbuio FJ, Churka S, Barth G, Corrêa JCL (2008)Effects of soil acidity amelioration by surface liming on no-till corn, soybean, and wheat root growth and yield. EuropeanJournalof Agronomy 28(1):57-64.

Campos JRR, Silva AC, Silva EB, Vidal-Torrado P (2014) Extração e quantificação de alumínio trocável em Organossolos. Pesquisa Agropecuária Brasileira49(3):207-2014.

Coelho MR, Vidal-Torrado P, Perez XLO, Martins VM, Vásquez FM (2010) Fracionamento do alumínico por técnicas de dissoluções seletivas em espodossolos da Planície Costeira do Estado de São Paulo. Revista Brasileira de Ciência do Solo 34(4):1081-1092.

CQFS-RS/SC (2004) Manual de adubação e calagem para os Estados do Rio Grande do Sul e de Santa Catarina. Porto Alegre. Sociedade Brasileira de Ciência do Solo - Núcleo Regional Sul, UFRGS.400p.

Cunha GOM, Almeida JA, Barboza BB (2014) Relação entre o alumínio extraível com $\mathrm{KCl}$ e oxalato de amônio e a mineralogia da fração argila, em solos ácidos brasileiros. Revista Brasileira de Ciência do Solo 38(5):1387-1401.

Cunha GOM (2017). Formas de alumínio em solos com altos teores trocáveis e toxidez na soja e no milho. Udesc (Tese de Doutorado em Ciência do Solo).

Cunha GOM, Almeida JA, Testoni S, Barboza BB (2015). Formas de alumínio em solos ácidos brasileiros com teores excepcionalmente altos de $\mathrm{Al}^{3+}$ extraível com KCl. RevBrasCien Solo 39(5):13621377.

Cunha GOM, Almeida, JA, Ernani PR, Pereira ER, SkoronskiE, Lourenço LS, Brunetto G (2018a). Chemical species and aluminum concentration in the solution of acid soils cultivated with soybean and corn under liming. Revista Brasileira de Ciência do Solo 42:1-16.

Cunha, G.O.M.; Almeida, J.A.; Ernani, P. R.; Pereira, E. R.; Brunetto, G (2018b). Composition, chemical speciation and activity of ions in the solution of Brazilian acid soils. Revista Brasileira de Ciências Agrárias 13(3):1-10.

De Conti L, Ceretta CA, Couto RR, Ferreira PAA, Silva LOS,PiccinR, Lourenzi CR,GirottoE, Brunetto G (2017). Aluminum species and activity in Sandy soil solution with pig slurry addition. Pesquisa Agropecuária Brasileira 52(10):914-922. 
Ebeling AG, Anjos LHC, Perez DV, Pereira MG, Valladares GS (2008). Relação entre a acidez e outros atributos químicos em solos com teores elevados de matéria orgânica. Bragantia67(2):429-439.

Embrapa (2013a)- Centro Nacional de Pesquisa de Solos. In: Anjos LHC, Silva LM, Wadt PGS, Lumbreras JF, Pereira MG, editores. Solos sedimentares em sistemas amazônicos- potencialidades e demandas de pesquisas [Guia de campo], 204p.

Embrapa (2013b)-. Centro Nacional de Pesquisa de Solos.Sistema Brasileiro de Classificação de Solo. 3. ed. Revisada e Ampliada. Brasília, DF; 353p.

Embrapa(2011a)-. Centro Nacional de Pesquisa de Solos. Sistema Brasileiro de Classificação de Solo. Projeto-Solos Alíticos. Pernambuco, Recife, Embrapa Solos; 63p.

Embrapa(2011b) - Centro Nacional de Pesquisas de Solos. Manual de métodos de análises de solos. 2.ed. Rio de Janeiro: Embrapa Solos; 230p.

Ernani PR, Bayer C, Almeida JA, Cassol PC (2007) Mobilidade vertical de cátions influenciada pelo método de aplicação de cloreto de potássio em solos com carga variável. Revista Brasileira de Ciência do Solo 21(2):393-402.

Ernani PR, Ribeiro MFS, Bayer C (2004) Chemical modifications caused by liming below the limedl ayer in a predominantly variable charge acidsoil. Communications in Soil Science and Plant Analysis 35 (5-6):889-901.

Ferreira DF (2014) Sisvar: a guide for its Bootstrap procedures in multiple comparisons. Ciência e Agrotecnologia38(2):109-112.

Fontana A, Pereira MG, Bernini TA, Dos Anjos LHC, Wadt PGS, Dos Santos LL (2017). Compartimentos da matéria orgânica de solos sob floresta no Estado do Acre. Floresta e Ambiente 24:1-8.

Gama JRNF, Kiehl JC (1999) Influência do alumínio de um Podzólico Vermelho-Amarelo do Estado do Acre no crescimento de plantas. Revista Brasileira de Ciência do Solo 23(2):475-482.

García-Rodeja E, Nóvoa JC, Pontevedra X, MartínezCortizas A, Buurman P (2004) Aluminum fractionation of European volcanic soils by selective dissolution techniques. Catena 56(1-3):155-183.

Gustafsson JP (2016). Visual Minteq, 3.1. Stockholm: KTH, Departamento of Land and Water Resources Engineering; [acessado em 20.10.16]. Disponível em: https://vminteq.Iwr.kth.se/download/
Hagvall K, Persson P, Karlsson T (2015) Speciation of aluminum in soils and stream Waters: The importance of organic matter. Chemical Geology 417(6):32-43.

Hashimoto Y, Smiyth TJ, Israel DW, Hesterberg D (2010) Lack of soybean root elongation responses to micromolar magnesium additions and fate of rootexuded citrate in acid soils. Journal of Plant Nutrition 33(2):219-239.

Hernández-Soriano MC (2012) The role of aluminumorgano complexes in soil organic matter dynamics. Soil Health Land Use Management 1:18-32.

Houba VJG, Temminghoff EJM, Gaikhorst GA, Vark W, van (2000) Soil analysis procedures using 0,01M calcium chloride as extraction reagent. Communications in Soil Science and Plant Analysis 31(9-10):1299-1396

Inda AV, Torrent J, Barrón V, Bayer, C (2010)Aluminum hydroxy-interlayered minerals and chemical properties of a subtropical Brazilian Oxisol under no-tillage and conventional tillage. Revista Brasileira de Ciência do Solo 34(1):33-41.

Júnior ABA, Nascimento CWA, Barros FMR (2015). Acidez potencial estimada pelo método do $\mathrm{pH}$ SMP em solo do Estado da Paraíba. Revista Brasileira de Ciência do Solo, 39(3):767-773.

Matúš $P$ (2007). Evaluation of separation and determination of phytoavailable and phytotoxic aluminium species fractions in soil, sediment and water samples by five different methods. Journal of Inorganic Biochemistry 101(9):1214-1223.

McKeague JA, Day JH (1996). Dithionite-and oxalateextractable $\mathrm{Fe}$ and $\mathrm{Al}$ as aids in differentiating various classes of soils. Canadian Journal of Soil Science 46:13-22.

Miguel PSB, GomesFT, RochaWSD, Martins CE, CarvalhoCA, OliveiraAV(2010) Efeitos tóxicos do alumínio no crescimento das plantas: mecanismos de tolerância, sintomas, efeitos fisiológicos, bioquímicos e controles genéticos. CES Revista 24(1):13-29.

Nolla A, Anghinoni I, Castaldo JH, Alves EOS, Neto L.VMN, Silva MAG, Muniz AS (2015) Disponibilidade de nutrientes e fitotoxidez de alumínio; influência da complexação por ligantes orgânicos na solução do solo. Journal of Agronomic Science 4 (n.especial): $1-16$.

Nolla A, Anghinoni I, Silva TRB, Silva MAG (2013b)Lime-phosphate relation and soybean growth in an oxisol from no-tillage system. Journal of Food Agriculture and Environmental 11(1):294-298. 
Nolla A, Korndörfer GH, Silva CAT, Silva TRB, Zucarelli V, Silva MAG (2013a)Correcting soil acidity with the use of slags. African Journal of Agricultural Research 8(41):5174-5180.

Olatunji OO, Oyeyiola Y, Oyediran, GO (2015) Assessment of dithionite and oxalate extractable iron and aluminum oxides on a landscape on basement complex soil in south-western Nigeria. Open Journal of Soil Science 5:266-275.

Rutkowska B, Szulc W, Hoch M, Spychaj-Fabisiak E (2015) Forms of Al in soil and soil solution in a longterm fertilizer application experiment. Soil Use and Management 31(1):114-120.

Santos PG, Almeida JA, Sequinatto L. (2017) Mineralogy of the clay fraction and chemical properties of soils developed from sedimentar lithologies of Pirambóia, Sanga-the-Cabral and Guará geological formations in Southern Brazil. Revista Brasileira de Ciência do Solo 41:1-19.

Schwertmann U (1964). The differentiation of iron oxide in soils by photochemical extraction with ammonium oxalate. Z. Pflanzenernährung Duengung Boden 105:194-201.

Schwertmann U (1973). Use of oxalate from Fe extraction from soils. Canadian Journal Soil Science53(2):244-246.

Shuman LM, Ramseur EL, Duncan RR (1990). Soil aluminum effects on the growth and aluminum concentration of sorghum. Agronomy Journal 82(2):313-318.

Shuman LM (1990). Comparison of Exchangeable Al, extractable Al, and $\mathrm{Al}$ in soil fractions. Canadian Journal of Soil Science 70(3):263-275.
Silva IR, Smyth TJ, Israel DW, Raper CD, Rufty TW (2001). Magnesium is more efficient than calcium in alleviating aluminum rhizotoxicity in soybean and its ameliorative Effect is not explained by the GouyChapman-Stern Model. Plant Cell Physiol42(5):538545.

Smyth TJ, Cravo MS (1992). Aluminum and calcium constraints to continuous crop production in a Brazilian Amazon Oxisol. AgronomyJournal84(5):843-850.

Spera ST, Escosteguy PAV, Santos HP, Klein VA (2014). Atividade do alumínio na solução do solo de um Latossolo Vermelho Distrófico submetido ao manejo do solo e de culturas. Pesquisa Agropecuária Ambiental 2(3):131-137.

Tandzi LN, Mutengwa CS, Ngonkeu LM, Gracen V (2018). Breeding maize for tolerance to acid soils: A review. Agronomy, 8(6):1-21.

Tedesco MJ, Gianello C, Bissani CA, Bohnen H, Volkweiss SJ. Análise de solo plantas e outros materiais. 2.ed. Porto Alegre: Universidade Federal do Rio Grande do Sul, 1995. (Boletim técnico, 5).

Teske R, Almeida JA, Hoffer A, Neto AL (2013) Caracterização mineralógica dos solos derivados de rochas efusivas no planalto sul de Santa Catarina, Brasil.Revista de Ciências Agroveterinárias12(2):187198.

Varadachari C, Goswami G, Ghosh K (2006). Dissolution of iron oxides. Clay Research 25:1-19.

Wadt PGS (2002). Manejo de solos do Estado do Acre. Rio Branco: Embrapa-Acre (Documentos, 79).

Zambrosi FCB, Alleoni LRF, Caires EF (2007). Teores de alumínio trocável e não trocável após calagem e gessagem em Latossolos sob sistema de plantio direto. Bragantia66(3):487-495. 